\title{
NARRATIVAS JUDICIALES
}

\author{
Michele Taruffo ${ }^{*}$
}

\begin{abstract}
RESUMEN
El artículo toma en consideración las teorías "narrativas" que desde algunos años han sido elaboradas a propósito de lo que sucede en el proceso, con particular atención del juicio sobre los hechos. Se consideran sobre todo tres problemas: la naturaleza de las narraciones, en general y en el contexto del proceso; la construcción de las narraciones relativas a los hechos de la causa, y el problema de la veracidad de las narraciones fácticas. La tesis fundamental es que no obstante se tengan en cuenta los aspectos "narrativos" que existen en el proceso, existe la necesidad de que los enunciados sobre los hechos sean sometidos a un juicio de verdad / falsedad por parte del juez. No es posible pensar que la decisión sea tomada sólo sobre la base de la coberencia narrativa de un relato que alguien ha narrado.
\end{abstract}

\section{NATURALEZA DE LAS NARRACIONES SOBRE LOS HECHOS DE LA CAUSA - CONSTRUCCIÓN DE LOS ENUNCIADOS SOBRE LOS HECHOS - VERDAD DE LAS NARRACIONES DE LOS HECHOS EN EL CONTEXTO DEL PROCESO}

\section{Judicial narratives}

ABSTRACT

The present article takes into account "narrative" theories that have been elaborated over the past few years concerning what takes place in the judicial process, particularly emphasizing the judgement about the facts. Three main problems are addressed: the nature of narrations, in general and within the judicial process context; the construction of narrations involving the facts of the case, and the issue of veracity in factual narrations. The fundamental thesis is that, despite taking on account the "narrative" aspects existing in the process, there is also a need for the statements regarding facts to be subjected by the judge to a truelfalse judgment. It is not possible to conceive that the decision should be taken only on the basis of the narrative coherence of a "story" someone has told.

\section{NATURE OF NARRATIVES REGARDING THE FACTS OF THE CASE - CONSTRUCTION OF STATEMENTS ABOUT FACTS - VERACITY IN THE FACTS NARRATIONS WITHIN THE JUDICIAL PROCESS CONTEXT}

\footnotetext{
* Abogado, Profesor de Derecho Procesal Civil en la Universidad de Pavía, Italia. Dirección electrónica: taruffo@unipv.it Artículo recibido el 31 de marzo de 2007 y aceptado para su publicación por el Comité Editorial el 18 de mayo de 2007. El artículo fue enviado originalmente por el autor en inglés. La traducción al español fue realizada por la abogada Verónica Undurraga Valdés. La edición definitiva del artículo contó con la colaboración de Daniela Accatino Scagliotti, profesora de Derecho de la Universidad Austral de Chile.
} 


\section{Credulidad o incredulidad}

$\mathrm{E}$ n la primera de sus Siete Noches, que es un comentario fascinante a la Divina Comedia de Dante, Jorge Luis Borges cita a Coleridge cuando dice que una condición previa necesaria para leer poemas es la "suspensión de la incredulidad". ${ }^{1}$ Este agudo comentario se sustenta en dos premisas implícitas aunque evidentes: a) que la incredulidad debe caracterizar nuestra aproximación a la experiencia común cotidiana como necesaria postura crítica dirigida a evitar que nos formemos o compartamos creencias falsas; b) que tenemos que ser crédulos para ser capaces de captar, entender y disfrutar fantasías, metáforas, ambigüedades, imaginerías, sentimientos, emociones, y todos los otros aspectos inusuales que se consideran típicos de la poesía.

El alcance de la afirmación de Coleridge podría ser fácilmente extendido, aunque no propiamente generalizado, porque -en algún sentido- cualquier tipo de experiencia estética puede pretender estar basada en un estado de credulidad. Por ejemplo, mirar un cuadro normalmente requiere una aproximación crédula: la apreciación de un Vermeer no supone un punto de vista escéptico respecto de si la luz en Delft a mediados del siglo XVII era realmente como Vermeer la pintó, aunque él fuera famoso por su intento de lograr una reproducción fidedigna de la realidad. Más aún, para poder apreciar un cuadro de Jackson Pollock o una escultura de David Smith uno no debe preguntarse si representan o no algo: es mucho mejor suspender la incredulidad y ser crédulos al disfrutar de las formas expresadas en ambas obras de arte. Una actitud similar e incluso más profunda debe ser mantenida mientras se escucha música, ya que la música es -como escribió Schopenhauer- ${ }^{2}$ la forma suprema de arte, la "catarsis estética”. En realidad, para apreciar a Wynton Marsalis y a Astor Piazzolla, para no pensar en Chopin o Brahms, es altamente recomendable estar en un estado mental de no incredulidad.

Volviendo a los textos escritos, uno podría decir que la suspensión de la incredulidad se necesita incluso al leer prosa y no sólo al leer poemas. ${ }^{3}$ Por ejemplo, es mejor ser crédulo al leer ciencia ficción, al menos para introducirnos en el contexto de la novela y durante el tiempo necesario para leerla. Ser sistemáticamente incrédulos -esto es, escépticos- respecto de la invasión terrestre por grandes y crueles criaturas extraterrestres puede ser racional, pero está lejos de ser la manera apropiada para leer a Wells. El mismo argumento se aplica en forma más general respecto de cualquier tipo de novelas, desde las de terror hasta las grandes obras maestras de la literatura de todos los tiempos y lugares. De alguna manera, por lo tanto, la distinción entre las aproximaciones crédulas e incrédulas corresponde a la distinción entre la fantasía y la creencia: cuando la que opera o debe operar es la fantasía, entonces la suspensión de la incredulidad es una condición previa de la experiencia humana; cuando el asunto es sobre creencias y en particular

\footnotetext{
${ }^{1}$ Ver Borges, Siete Noches, Buenos Aires, 2005, p. 16.

${ }^{2}$ Ver Schopenhauer, Die Welt als Wille und Vorstellung, Zürich, 1988, Band I, § 52, p. 338.

${ }^{3}$ En su Quinta Noche, refiriéndose a la poesía, Borges dice que es un error creer que la prosa está más cercana a la realidad que la poesía: ibídem, p. 116.
} 
sobre creencias verdaderas sobre los sucesos del mundo humano y material, una actitud escéptica e incrédula es probablemente mucho más racional, aunque probablemente sea mucho menos fascinante y atractiva. ${ }^{4}$

Si, como parece al menos en una primera mirada, dicha distinción tiene sentido, entonces puede ser usada como antecedente para ocuparnos de otros ámbitos narrativos más acotados y en particular del domino definitivamente más acotado de las "narrativas judiciales."

\section{NARRATIVAS}

Uno de los términos más en boga y más sobredimensionados de las últimas dos o tres décadas es "narrativa”. Se ha transformado en una especie de ícono de la llamada aproximación postmoderna a muchas (quizá demasiadas) cosas, como la literatura, la crítica literaria, la filosofía e incluso la teoría jurídica. ${ }^{5}$ Por su uso extremadamente amplio y variable y por la multiplicidad de ámbitos en los que se emplea, es imposible (en este contexto, por cierto, y probablemente en general) considerar todos los aspectos que dicen relación con narrativas. Sin embargo, desde que el "giro narrativo" se ha transformado en un lugar común también en el discurso sobre la prueba y la decisión judicial, ${ }^{6}$ es posible al menos hacer algunos comentarios aislados, no sistemáticos y ciertamente incompletos, sobre el rol de las narraciones en los contextos procesales y probatorios. En esta perspectiva, puede asumirse la existencia de una conexión -quizás una equivalencia- entre el discurso acerca de las "narrativas" y el discurso acerca del story-telling. En alguna medida, los contextos culturales y las connotaciones de los dos conceptos pueden divergir pero, desde la perspectiva procesal, puede asumirse sin problemas que las "historias" que son contadas en un procedimiento judicial son -o al menos pueden ser tratadas como- narraciones. ${ }^{7}$

Concentrarse en narraciones judiciales implica que muchos debates sobre las narrativas en general deben ser dejados de lado. Por ejemplo, los ataques postmodernos en contra de los llamados Grandes Relatos, tales como la Historia, el Progreso, la Razón, la Verdad, y otras, no pueden ser discutidos aquí como merecerían, ${ }^{8}$ y lo mismo debe

${ }^{4}$ De hecho, la realidad -aunque misteriosa- es mucho más simple que su descripción literaria: ver Borges, ibidem, pp. 114, 117.

${ }^{5}$ Ver, por ejemplo, Law's Stories, Narrative and Rhetoric in the Law, ed. by P. Brooks \& P. Gewirtz, New Haven-London, 1996.

${ }^{6}$ Ver principalmente Twining, Rethinking Evidence, Exploratory Essays, 2nd ed., Cambridge a.o., 2006, pp. 280, 286, 332. Ver también Burns, Fallacies on Fallacies: A Reply, en 3 Int'l Comment. On Evidence 2005, art. 4, 1, para mayores referencias. El ejemplo más interesante de esta perspectiva es probablemente Jackson, Law, Fact and Narrative Coberence, Merseyside, 1988.

${ }^{7}$ Para una postura similar, ver Twining, supra n. 6, at 291.

8 Acerca de la "muerte de los Grandes Relatos" en la filosofía postmoderna, ver, por ejemplo, Litowitz, Postmodern Philosophy and Law, Lawrence, Kansas, 1997, p. 10. 
decirse respecto del contraste entre "fundacionalistas" y "antifundacionalistas". 9 Basta con decir que actualmente parecen un poco triviales y extemporáneas: por lo menos desde mediados del siglo XIX y la primera década del siglo XX, ${ }^{10}$ y especialmente después de la segunda guerra mundial, ninguna persona educada y culta siguió creyendo en Grandes Relatos. De hecho, largo tiempo antes de Baudrillard, ${ }^{11}$ la cultura europea conoció a Jean-Paul Sartre y Albert Camus, para no mencionar a Nietzsche y a todos los irracionalistas de los que trata Lukács en Zerstörung des Vernunft. En aquel tiempo los intelectuales europeos estaban perfectamente conscientes del fin de las certezas propias del siglo XIX. Sin embargo, Baudrillard no fue en ningún caso el único ejemplo de un filósofo postmoderno que redescubre gastados lugares comunes y los reinterpreta en un estilo grandilocuente como si las connotaciones retóricas y apocalípticas fueran señal de un pensamiento profundo y novedoso.

Por otro lado, para definir el nivel de discurso que sería útil para hablar de narrativas judiciales, puede ser incluso insuficiente referirse a los relatos cotidianos y concentrarse en el ámbito jurídico. El movimiento "Derecho y Literatura" ${ }^{12}$ ha dado muchas luces en asuntos jurídicos, pero también mucha cháchara académica para la hora del cóctel. No todo lo que se dice resulta significativo, en realidad, y cuando lo es se refiere principalmente a ideas vagas y variables sobre "narrativas jurídicas" en las que la distinción entre hechos y derecho normalmente es difusa ${ }^{13}$ y los "hechos judiciales" se mezclan en una indistinta "conversación literaria sobre el derecho".

Con esto no se quiere decir que la teoría de las narrativas, especialmente en la perspectiva de la psicología social, no tenga nada relevante que decir acerca del story-telling judicial. Muy por el contrario. Como veremos, esa teoría provee varias pistas que son extremadamente útiles en un análisis acabado de las narrativas judiciales. Las advertencias recién mencionadas tienen por objeto subrayar que la máxima de los abogados medievales distingue frequenter es válida también aquí: en efecto, es necesario distinguir para lograr una comprensión apropiada de las narrativas judiciales.

Hablando del story-telling jurídico y judicial, Twining, con justa razón, ha subrayado frecuentemente que las "historias" son a la vez necesarias y peligrosas. ${ }^{14}$ Las historias y narraciones son necesarias tanto en los contextos judiciales como extrajudiciales, porque son los medios principales por los cuales fragmentos de información y "piezas” de sucesos que están dispersos pueden ser combinados y organizados como un conjunto de hechos coherentes y significativos: las historias modelan nuestra experiencia y nos proveen con

\footnotetext{
${ }^{9}$ Respecto de este tema ver, por ejemplo, Minda, Postmodern Legal Movements. Law and Jurisprudence at the Century's End, New York-London, 1995, pp. 161, 164.

${ }^{10}$ Ver el complejo análisis desarrollado por Burrow, The Crisis of the Reason. European Thought, 18481914, New Haven-London, 2000.

${ }^{11}$ Para un extenso análisis crítico del pensamiento de Baudrillard ver Norris, What's Wrong with Postmodernism. Critical Theory and the End of Philosophy, Baltimore, 1990, p. 164.

${ }^{12}$ Para una breve descripción del movimiento, ver Minda, supra n. 9, p. 149.

13 Ver infra, \$2.2.

${ }^{14}$ Ver Twining, supra, n. 6, pp. 283, 336, 445.
} 
esquemas del mundo, ${ }^{15}$ pueden ser entendidas como "elaboraciones interpretativas de los sucesos" que dan una forma posible, un modelo, a una serie de datos informes. ${ }^{16}$ Ellas proveen una "heurística", esto es, un método para descubrir lo que realmente ocurrió. ${ }^{17}$ Sin embargo, su característica principal es que ellas solamente proponen posibilidades, no importando qué tan lejanas ellas estén de la realidad. ${ }^{18}$ En ese sentido, las narrativas son como el diseño que forma un mosaico a partir de un montón de piezas de vidrio de colores. ${ }^{19}$

Por otro lado, las historias "se vuelven sospechosas" 20 y peligrosas, porque abren la puerta a la vaguedad, la variabilidad y la manipulación en la reconstrucción de los hechos ${ }^{21}$ dependiendo del punto de vista, los intereses y los propósitos de los sujetos que cuentan las historias en un determinado momento y contexto. Esto es cierto en general, ${ }^{22}$ pero especialmente en el contexto judicial. Como veremos más adelante, un procedimiento judicial no incluye solo una narrativa o story-telling: es una situación compleja en la que varias "historias" son construidas y contadas por diferentes sujetos, desde diferentes puntos de vista y de maneras distintas. Particularmente serios son los peligros de errores, relatos incompletos, manipulaciones y reconstrucciones incorrectas de los hechos, que pueden llevar a malos entendidos y errores dramáticos en la decisión final de un caso.

\subsection{Un experimento mental}

Existe una gran variedad de narrativas acerca de hechos. El tipo más común está representado por las novelas y especialmente por aquellas novelas que están redactadas en la forma de relatos de historias. Existe toda una rama de la crítica literaria, llamada narratología, se ocupa de los problemas relativos a las estructuras, las características y las técnicas de la narración; pero no es necesario que nos hagamos directamente cargo aquí de todos esos sofisticados temas. ${ }^{23}$ Más bien, podemos tomar un ejemplo muy simple y ver qué nos puede decir -en una especie de experimento mental-acerca de las narrativas y de sus aspectos epistémicos, con el fin de subrayar algunas características que parecen ser típicas de los relatos judiciales.

${ }^{15}$ Ver especialmente Bruner, Making Stories. Law, Literature, Life, Cambridge, Mass, London, 2002, 9, p. 25.

${ }^{16}$ Ver Borutti, Filosofia dei sensi, estetica del pensiero tra filosofia, arte e letteratura, Milano, 2006, p. 31.

17 Ver Burns, ibidem.

18 Ver Borutti, ibidem.

${ }^{19}$ Como veremos después, sin embargo, la relación de las partes con el todo no está exenta de problemas: ver infra, $\$ 4$.

${ }^{20}$ Ver Bruner, supra n. 15, p. 43.

${ }^{21}$ Ver Menashe-Shamash, The Narrative Fallacy, en 3 Int'l Comment. On Evidence 2005, art. 3, 8.

22 Ver Bruner, supra n. 15, p. 23.

${ }^{23}$ Ver Twining, supra n. 6, p. 318. 
El ejemplo (escogido entre miles que podrían servirnos igualmente bien) es la muy conocida novela de suspenso de John Grisham The Broker. Las razones de esta elección son básicamente las siguientes: a) cientos de miles o millones de lectores la conocen; b) una parte importante de la historia sucede en Bolonia, una ciudad que conozco muy bien.

Cuando una Lectora No Informada (LNI) (esto es, una lectora que no sabe nada de Bolonia) lee la novela, encuentra descripciones de lugares, plazas, calles, restaurantes, iglesias y otros sitios en que ocurre la acción. Esas descripciones son frecuentemente detalladas y realistas: reflejan muy bien las imágenes y la atmósfera de la ciudad y de sus lugares y formas de vida representativos. De hecho, Grisham vivió en Bolonia algunos meses solo con el fin de reunir información e impresiones sobre los lugares que iba a describir. Esto le da a la novela un sabor de autenticidad, coherencia y realismo que se aprecia en sí mismo, y no solamente porque agregue una fuerte sensación de credibilidad a las aventuras del Broker. Cuando una Lectora Informada (LI) (esto es, una lectora que conoce bien Bolonia) lee la novela, su actitud casi instintivamente se transforma, y no sólo por el sentimiento de "familiaridad" que la LNI no puede tener. Con las descripciones de Grisham, la LI puede sentirse inclinada a distinguir enunciados que son epistémicamente diferentes entre ellos:

a) Algunos (muchos) de estos enunciados son verdaderos. Por ejemplo, cuando Grisham escribe que en el centro de Bolonia hay dos torres medievales llamadas Asinelli y Garisenda, está realizando una aserción verdadera, porque en la Bolonia que existe en el mundo de la realidad empírica y material esas torres realmente existen con esos nombres. Igualmente, la afirmación de que en la Via Zamboni n. 22 existe un edificio en el cual está ubicada la Facultad de Derecho de la Universidad de Bolonia, también es verdadera. Hasta aquí vamos bien: esos enunciados, como muchos otros, suenan verdaderos a la LI porque reflejan la realidad material de los lugares que describen. Para la LNI, ellos pueden sonar verosímiles, y para ella eso es suficiente.

b) Cuando Grisham escribe que en el edificio de la Facultad de Derecho están los estudios de los profesores que enseñan en la facultad, hace una afirmación que es verosímil, porque en muchos casos -o en la mayoría- las salas de los profesores están ubicadas en los edificios principales de las facultades de Derecho. Por lo tanto, esa aserción es verosímil porque corresponde a lo que normalmente ${ }^{24}$ ocurre. El problema es que, en el caso específico, el enunciado es verosímil, pero falso, porque los estudios de los profesores de Derecho de Bolonia no están ubicados en ese edificio. No hay nada asombroso en eso: muchas cosas que parecen verosímiles solo porque corresponden al id quod plerumque accidit en realidad no existen. Todo esto es irrelevante para la LNI: para ella la verosimilitud de la afirmación sobre las

${ }^{24}$ Acerca del concepto epistémico de verosimilitud y su relación con el concepto de verdad ver principalmente Niiniluoto, Trutblikeness, Dordrecht a.o. 1987. La idea de verosimilitud de una aserción sobre un hecho como correspondencia de esa afirmación con lo que normalmente sucede está desarrollada en Taruffo, La prova dei fatti giuridici. Nozioni generali, Milano, 1992, p. 158. Respecto de la ambigüedad de lo "normal”, ver Hacking, The Taming of Chance, Cambridge, 2004, p. 161. 
salas de profesores es suficiente para asegurar la coherencia de la narración. La situación de la LI es diferente: ella entiende que la coherencia del relato se mantiene porque la afirmación es verosímil, pero se da cuenta que la narración está pasando de la descripción de la realidad al nivel de la invención y la fantasía, porque sabe que la realidad es diferente de la descripción ofrecida por Grisham.

c) Cuando Grisham escribe que en el edificio de la Facultad de Derecho además está el estudio del profesor Rudolph Viscovitch, hace una afirmación que es descriptivamente falsa, pero que no pretende ser verdadera, y ni siquiera verosímil, y que no puede ser tomada como verdadera o verosímil. Efectivamente, todo lector, informado o no informado, ya sabe que el profesor Rudolph Viscovitch no existe y que es solamente un personaje creado por el escritor: queda claro por la narración del primer encuentro del Broker y el profesor en un café, unas pocas páginas antes. De hecho, la coherencia narrativa de la historia está asegurada, porque el profesor Viscovitch es descrito como un hombre barbado, de edad mediana, muy "normal", lo que es un tipo humano común que perfectamente podría ser la imagen de un profesor, y no como una criatura verde venida de Marte.

Desde el punto de vista de la coherencia narrativa, no hay diferencia entre la situación de la LNI y la de la LI: ambas pueden apreciar el orden y la conexión de los sucesos que se describen. Sin embargo, la LNI percibe solamente la coherencia de la narración y la verosimilitud uniforme de los sucesos, mientras que la LI conoce que algunas partes de la historia son verdaderas, mientras que otras partes son falsas, aunque verosímiles. Puede apreciar el esfuerzo de Grisham para insertar su historia en un contexto verídico, pero no puede percibir un giro continuo y reiterado desde la realidad a la ficción y de la ficción a la realidad. En una palabra: la LNI y la LI leen la misma narración desde dos puntos de vista epistémicamente distintos. La LNI no sabe qué es verdadero y qué es falso en la historia de Grisham, pero no está interesada en saberlo: lo que está leyendo es -después de todo- una ficción, y no se espera de una ficción que sea una descripción verídica de nada. La LI también está leyendo una ficción y no espera que la historia sea verídica, es solamente una ficción: sin embargo, sabe qué es verdadero y qué es ficticio en la historia de Grisham.

Ahora, dejando al Broker a su suerte, imaginémonos que el New York Times informa que "el profesor Rudolph Viscovitch fue asesinado en su despacho en la Facultad de Derecho de Bolonia, Via Zamboni, 22, por un estudiante decepcionado”, y dice que esa afirmación fue formulada en la acusación redactada por el fiscal de Bolonia, fue incluida en el testimonio dado por un/a testigo y además aparece en la sentencia final que condenó al estudiante a las penas más severas (ya que matar profesores de derecho es el peor de los crímenes, incluso para alumnos decepcionados). Tanto la LNI como la LI, al leer la noticia, no podrían evitar la fuerte sensación de incomodidad y -esencialmente- de incredulidad. Ellas saben que -salvo por una muy improbable coincidencia de nombres- el profesor Rudolph Viscovitch no existe fuera de la historia de Grisham. Descartando errores en el reportaje del New York Times, tanto la LNI como la LI deben entonces concluir que las narraciones acerca del asesinato del profesor Viscovitch son falsas, aunque tomadas en sí mismas parezcan coherentes, plausibles y, por lo tanto, creíbles. En consecuencia, la LNI 
y la LI pensarían que este es un claro caso de error judicial fundado en una imputación falsa, un testimonio falso y una sentencia equivocada.

Las razones por las cuales la LNI y la LI reaccionan en forma diferente al leer a Grisham y al leer el reportaje del New York Times son muy claras: al leer a Grisham ellas suspendieron su incredulidad porque estaban conscientes de que estaban leyendo ficción, y no se espera que los relatos ficticios sean descriptivamente verdaderos. Cuando, como en el caso de la LI, uno sabe que algunas afirmaciones incluidas en la novela son verdaderas porque lo que dicen corresponde a lugares reales en Bolonia, esto puede agregarle un sabor de realidad al relato. Pero incluso la LNI, que no puede percibir el sabor de realidad, puede apreciar perfectamente la plausibilidad y el "realismo verosímil" de la historia. Pero cuando un lector sabe que no está leyendo ficción, y que está leyendo la narrativa de hechos relativos a un caso judicial real, su actitud es completamente diferente: asume que las historias sobre esos hechos deben ser verdaderas (no solo verosímiles), y por lo tanto no puede sino ser incrédula cuando lee una historia judicial que sabe que es falsa. Lo principal es que no se espera que algunas historias sean verdaderas (incluso si son al menos parcialmente verdaderas), y por lo tanto el hecho de que sean descriptivamente falsas (en todo o en parte) no es relevante: un relato puede ser narrativamente bueno cuando es coherente, consistente, creíble, normal, familiar, verosímil y, por lo tanto, persuasivo. Pero un buen relato no necesita ser verdadero. ${ }^{25}$ Respecto de otras historias, por el contrario, se espera que sean ciertas y por lo tanto el lector permanece siendo "incrédulo" hasta que quede satisfecho de que la narrativa corresponde a la realidad material de los acontecimientos. Se trata solo de un asunto de contextos diferentes y de narrativas diferentes. Después de todo, tanto los LNIs como los LIs nunca deben olvidar que el derecho no es literatura, ${ }^{26}$ y que una buena narrativa en literatura puede ser una mala narrativa en derecho. En el fondo de este asunto hay un problema fundamental que dice relación con el concepto de verdad: la verdad se relaciona con el contexto al que pertenece. Por lo tanto, contextos diferentes pueden adoptar distintos conceptos de verdad y es la diferencia en el contexto lo que determina diferentes ideas sobre la verdad. Es entonces en consideración al contexto que podemos decidir si una aserción describe el mundo en su realidad empírica, y por consiguiente tiene pretensiones de ser verdadera, o si lo que la historia busca es crear un mundo fantástico donde no se trata de un asunto de verdad empírica y solamente cabe pensar en una verdad "interna" a ese universo fantástico. ${ }^{27}$ El contexto judicial es un contexto en que la verdad empírica es necesaria; una novela es un contexto en el cual la "verdad narrativa" es simplemente algo que pertenece al mundo fantástico creado por el novelista. Grisham, al igual que muchos otros novelistas, mezcla los contextos usando también enunciados que son empíricamente verdaderos, pero lo hace solo como

${ }^{25}$ Ver Twining, supra n. 6, pp. 283, 293, 337. Respecto de la relación verdad/falsedad y la calidad narrativa de las historias, ver también infra, $\S 5$.

26 Ver Gewirtz, en Law's Stories, supra n. 5, p. 5.

27 Ver Prandi, Metafore e verità, en Confini della filosofia. Verità e conoscenza nella filosofia contemporanea, a cura di S. Borutti e F. Papi, Como-Pavia, 1994, p. 165. 
un recurso literario; de todas formas un concepto diferente de verdad está operando: es la verdad "interna" a la historia ficticia del Broker.

\subsection{Narrativas y bechos}

Incluso cuando el discurso usual sobre narrativas y story-telling se remite específicamente a los contextos judiciales, suele hacer referencia en forma general a todos los elementos del caso, juntando en un "todo" inseparable tanto los aspectos fácticos como los jurídicos de la situación de que se trata. ${ }^{28}$ Esto puede deberse a varias razones. Una razón puede ser que los abogados tienden a hablar mucho más del derecho que de los hechos. Otra razón puede ser que la práctica del story-telling jurídico, y del story-telling judicial también, tienda a borrar varias distinciones, como aquellas existentes entre hecho y derecho y entre hecho y valor. ${ }^{29}$ Una tercera razón puede ser que la distinción derecho-hecho sea un antiguo y eterno problema no solo en los sistemas de common law, donde tiene que ver básicamente con la separación de funciones entre el juez y el jurado. ${ }^{30}$ Aún en los sistemas de civil law, en los que no se conoce el jurado civil y donde la distinción entre derecho y hecho se usa especialmente con el fin de definir los límites de facultades de las cortes supremas, ella resulta confusa y problemática y tiene significados diversos en distintos contextos. ${ }^{31}$ Una cuarta razón importante es que definir un "hecho" puede dar lugar a un conjunto de preguntas filosóficas, por lo que uno tiende a dejar a un lado cualquier intento de hablar específicamente de "hechos". No hay que asombrarse, por lo tanto, de que la actual teoría del story-telling no considere la distinción entre derecho y hecho.

Todas estas dificultades deben ser consideradas cuando se habla de narrativas judiciales. Sin embargo, el discurso puede ser menos general y vago que lo que es usual: no hay duda de que los relatos judiciales deben referirse también a los aspectos jurídicos del caso, pero esto no significa que sea imposible pensar en narraciones sobre hechos. Tampoco hay duda de que -citando a William Twining nuevamente- los hechos tienen que ser "tomados en serio": 32 muchos casos se ganan o pierden "en los hechos", dependiendo de si el demandante tuvo éxito en probar los hechos en que se fundamenta su demanda; muchos "casos difíciles" son difíciles porque los hechos son demasiado complejos como

${ }^{28}$ Ver, por ejemplo, Twining, supra n. 6, pp. 290, 296.

${ }^{29}$ Ver Twining, supra n. 6, p. 336.

${ }^{30}$ Ver e.g. Tillers, en Wigmore, A Treatise on the Anglo-American System of Evidence in Trials at Common Law, vol. I, rev. $3^{\text {rd }}$ ed., Boston-Toronto 1983, 2, nota al pie. 2; Weiner, "The Civil Jury Trial and the Law-Fact Distinction", en 54 Cal. L. Rev. 1966, 1867; Id.; "The Civil Non-Jury Trial and the Law-Fact Distinction", ibidem , 55, 1968, 1020. Respecto de la regla tradicional "ad queastionem facti non respondent judices, ad quaestionem juris non respondent juratores", ver Thayer, A Preliminary Treatise on Evidence at the Common Law, Boston, 1898 (repr. New York 1969), p. 183.

31 Ver, por ejemplo, Marty, La distinction du fait et du droit. Essay sur le pouvoir de contrôle de la Cour de Cassation sur les juges du fait, Paris, 1929. Ver también los ensayos de Foriers, Ascarelli, Rivero, Buch y Roland en el libro Le fait et le droit. Etudes de logique juridique, Bruxelles, 1961, pp. 51, 113, 149, 175.

${ }^{32}$ Ver Twining, supra n. 6, pp. 14, 417. 
para ser subsumidos bajo una norma legal clara; más aun, en el contexto judicial los hechos son el punto de referencia de todo el aparato de la prueba. Por lo tanto, si uno tiene alguna experiencia en la práctica de los procedimientos judiciales, negar la posibilidad de hablar separadamente de "narrativas relativas a los hechos" parece no tener sentido. Entonces puede razonablemente asumirse que los hechos del caso pueden distinguirse del "derecho del caso", aunque claramente estas dos dimensiones estén íntimamente conectadas. Es fácil notar que para que el derecho y los hechos estén conectados, ellos deben ser concebibles como distintos o al menos como distinguibles. En realidad, los hechos del caso pueden ser identificados como tales y ser separados de las dimensiones jurídicas del caso. ${ }^{33}$ Por cierto que cuando se habla de "hechos" no se hace referencia a los hechos en su existencia material y empírica: las narraciones solo pueden referirse a "enunciados acerca de hechos". Un enunciado acerca de un hecho es cualquier enunciado en el que se describe que un evento ocurrió "de tal y cual manera” en el mundo real (el que, por supuesto, se asume existente y no meramente imaginado o soñado). ${ }^{34}$ En tanto describe algo que se asevera haber ocurrido en el dominio de la realidad, ese enunciado es apofántico, esto es: puede ser verdadero o falso. ${ }^{35}$

Hay al menos un sentido en el cual la distinción entre derecho y hecho es necesaria y, en consecuencia, también posible. Esa distinción es ineludible cuando el problema es establecer qué puede y qué deber ser probado en un procedimiento judicial. El principio general comúnmente reconocido es que el derecho no puede ser probado en el sentido propio y específico de la palabra: jura novit curia, y corresponde al juez conocer el derecho aplicable para decidir el caso. Entonces, solo los hechos (es decir, enunciados relativos a hechos) son objeto de prueba. Las afirmaciones relativas a los aspectos jurídicos del caso son objeto de decisión, interpretación, argumentación y justificación, pero no pueden ser probadas. Las aserciones relativas a hechos también son materia de decisión, interpretación, argumento y justificación, pero sobre todo -y finalmente- ellas pueden ser probadas como verdaderas o falsas. La relevancia de los elementos de prueba, es decir, la condición básica para su admisibilidad, se establece por referencia a las aserciones fácticas relativas al hecho físico en cuestión, no por referencia a los argumentos jurídicos proporcionados para encuadrar jurídicamente el caso. Esa distinción entre derecho y hecho no necesita ulterior análisis: los principios que rigen la admisibilidad y la valoración de las pruebas ofrecen una base suficiente para determinar qué merece ser considerado como "hecho" en el contexto de un caso judicial.

Cuando se trata de los hechos que están involucrados en un proceso judicial, no hay necesidad de ahogarse en una vorágine de asuntos filosóficos y epistemológicos. ${ }^{36}$

33 En otro lugar desarrollé el argumento en que se basa esta afirmación: ver Taruffo, supra n. 24, pp. 67,71 .

${ }^{34}$ Ese supuesto se basa en un conjunto de condiciones filosóficas, epistémicas e incluso éticas que no pueden ser discutidas aquí y que serán analizadas en otra parte. En términos generales, ver Goldman, Knowledge in a Social World, Oxford, 1999, pp. 3, 41, 69.

35 Respecto de esta característica de las afirmaciones de hecho, ver también infra $\S 5$.

${ }^{36}$ Respecto de algunos de estos temas, ver Taruffo, supra n. 24, pp. 67, 71. 
De hecho, los acontecimientos que son relevantes en la administración de justicia son tranches de vie, es decir, eventos o conjuntos de eventos que tienen que ver con la vida de la gente. Esto significa que normalmente estos pueden ser determinados a un nivel macro: incluso cuando resulten involucradas la microfísica o la genética, el objetivo final es siempre probar "un hecho de la vida de la gente". Normalmente ellos pueden ser determinados con suficiente especificidad por referencia a la situación jurídica de los sujetos involucrados.

Hay, sin embargo, algunos aspectos de la definición de los "hechos de la causa" que vale la pena considerar con mayor detenimiento. En primer lugar: esos hechos son seleccionados y determinados de acuerdo con su relevancia en el caso: los hechos y las circunstancias irrelevantes no necesitan ser tomados en cuenta al definir qué hechos deben ser probados. El estándar para evaluar la relevancia es doble. Un hecho es jurídicamente relevante (en la jerga jurídica norteamericana: "material”) cuando corresponde con el supuesto de hecho definido por una norma jurídica que se considera posiblemente aplicable al caso. Las reglas definen "tipos de hechos" ("fact-types") y los hechos concretos son relevantes (como "fact-token") cuando corresponden a esos tipos. ${ }^{37}$ Entonces los hechos jurídicamente relevantes son definidos como tales por referencia a la norma que es vislumbrada como estándar para tomar la decisión final: esos hechos son los facta probanda básicos, esto es, el objeto principal de prueba, y por lo tanto el contenido de las aserciones fácticas más importantes. Un hecho es lógicamente relevante cuando, no siendo en sí mismo un facta probanda básico, puede ser usado como una premisa, esto es, como un punto de partida, para inferencias que posiblemente lleven a una conclusión acerca de la verdad o falsedad de un enunciado relativo a un hecho principal. Un hecho lógicamente relevante merece ser probado cuando su conocimiento es útil para inferir la verdad o falsedad de ese tipo de enunciados. ${ }^{38}$

Los hechos pueden ser simples, cuando un solo evento involucra a una o más personas en un momento específico en el tiempo, o pueden tener distintos grados de complejidad, cuando, por ejemplo, varios eventos conexos involucran a varias personas, o pueden ser extremadamente complejos, cuando una serie de eventos están repartidos en el tiempo e involucran a cientos o millones de personas. ${ }^{39}$ En consecuencia, algunas veces pueden ser descritos por uno o solo unos pocos enunciados simples, y otras veces

${ }^{37}$ Esta conexión es conocida y ampliamente analizada por la teoría jurídica continental. Sería imposible dar referencias adecuadas aquí. Sin embargo, ver al menos los textos clásicos en el tema: Engisch, Logische Studien zur Gesetzesanwendung, 2. Aufl., Heidelberg, 1960, pp. 19, 37, 83. Ver también, para más referencias, Taruffo, supra n. 24, p. 74.

${ }^{38}$ La relevancia lógica es el estándar básico para la decisión sobre si admitir o excluir un elemento de prueba, sobre la base del principio frustra probatur quod probatum non relevat. Sobre este principio general y para mayores referencias, ver Taruffo, supra. n. 24, p. 338; Id, Studi sulla rilevanza della prova, Padova, 1970. El principio es reconocido en todos los sistemas procesales y contenido en un conjunto de normas específicas. Ver, por ejemplo, la Regla 410 de las Federal Rules of Evidence estadounidenses.

${ }^{39}$ De hecho, la "complejidad fáctica" es uno de los principales elementos de un litigio complejo, como sucede en el caso de responsabilidad masiva y acciones de clase: ver Manual for Complex Litigation, Fourth, Federal Judicial Center, 2004, pp. 242, 341. 
solo pueden ser descritos mediante historias largas y complicadas. Sin embargo, así como los eventos complejos pueden ser pensados y analizados como compuestos por conjuntos de eventos singulares, las narrativas complejas están compuestas por cadenas de aserciones específicas: desde el punto de vista de la prueba, cada aserción específica debe ser probada. Por ejemplo, si el "hecho" es una cadena causal compleja como “A $\rightarrow \mathrm{B} \rightarrow \mathrm{C}$; D", es necesario que se aporten elementos de prueba que puedan sustentar A, B, C, D, y todas las relaciones causales que las conectan. ${ }^{40}$

Los hechos pueden involucrar no solo eventos ocurridos en la realidad material, como un accidente de tráfico, sino también actitudes o estados de ánimo, como ocurre con la intención o mens rea, o pueden estar compuestos tanto de elementos "materiales" como "psíquicos". Estos hechos pueden dar lugar a dificultades probatorias, pero, no obstante eso, deben ser acreditados como hechos: esto significa que los enunciados que los describen también deben ser probados como verdaderos o falsos. ${ }^{41}$

\subsection{Story-tellers}

Un aspecto que a veces se pasa por alto o se subestima en los discursos relativos a las narrativas judiciales es que en el contexto judicial no se da solamente una narrativa continua. Una mirada más detenida a la administración de justicia en la perspectiva narrativa muestra que de hecho está integrada por un número variable de "historias" relatadas por diferentes sujetos, en diferentes formas y con diferentes propósitos. ${ }^{42}$ No se trata solo de que haya varios sujetos que hablan desde puntos de vista diferentes ${ }^{43}$ y desde perspectivas particulares. ${ }^{44}$ En los procesos judiciales las historias son contadas por los abogados con ánimo de confrontación y se encuentran en oposición una con otras: ${ }^{45}$ el contexto judicial tiene la estructura de una controversia, en la que los abogados presentan relatos alternativos y opuestos de los hechos. ${ }^{46}$ Entonces, quien juzga acerca de los hechos (trier of fact) debe tomar una decisión a favor de uno de los posibles relatos. Las características particulares de las "historias" que son relatadas en el contexto judicial merecen algunos otros comentarios, especialmente desde el punto de vista de los "story-tellers judiciales" más importantes y característicos.

a) Abogados. En relación con las narraciones de los abogados, Twining pone el acento en que los mecanismos de una efectiva defensa "involucran el socavamiento del argumento racional", "incluyen técnicas para mantener al margen información relevante",

${ }^{40}$ Para un análisis más amplio de la prueba de la causalidad, ver Taruffo, "La prova del nexo causale", en Riv.crit.dir.priv., 2006, p. 101.

${ }^{41}$ En otro lugar discuto el problema relativo a esa peculiar clase de hechos: ver Taruffo, supra, n. 24, p. 121.

\footnotetext{
42 Una afirmación similar en Jackson, supra n. 6, p. 85.

43 Ver Twining, supra n. 6, 130, 132. Ver también a Gewirtz, supra n. 26, p. 8.

${ }^{44}$ Ver Bruner, supra n. 15, p. 23.

45 Ver Bruner, supra n. 15, p. 43: Gewirtz, supra n. 26, p. 7; Burns, supra n. 6, p. 2.

46 Ver Amsterdam-Bruner, Minding the Law, Cambridge, Mass.-London, 2002, p. 173.
} 
"para blanquear los hechos" y "para aprovechar medios de persuasión no racional", ${ }^{47}$ y que todo esto se hace porque la primera tarea de un abogado es persuadir al tribunal de decidir a favor de su cliente. ${ }^{48}$ En consecuencia, las narraciones de los abogados tienden a incluir una manipulación de los hechos, orientada a ganar el caso. ${ }^{49}$ Otros autores comparten esta visión crítica y escéptica sobre la forma en que los abogados preparan y presentan sus historias y enfatizan el hecho de que esas narraciones muchas veces son engañosas y desorientadoras. ${ }^{50} \mathrm{Si}$, como parece, estas son descripciones realistas de la práctica narrativa de los abogados, surgen algunas preguntas. Se hará referencia enseguida a dos de esas preguntas, aunque con el solo fin de llamar la atención sobre ellas y sin la discusión completa que merecerían. Luego se dedicarán algunos comentarios adicionales a una tercera pregunta.

La primera pregunta dice relación con la ética profesional de los abogados y considera si, y en qué medida, la omisión voluntaria o la distorsión de hechos relevantes por parte de ellos con el propósito de ganar el caso es legítima y justificada. Cabe preguntarse si debiera haber una "ética de la narrativa del abogado" que prohíba a éste presentar un relato de los hechos que considera falso. ${ }^{51}$ Sin embargo, la respuesta al problema de si el abogado está o no obligado a decir la verdad al narrar los hechos puede ser desconcertante: el estudio más reciente y autorizado sobre ética jurídica solo tiene una breve referencia a ella, que dice que el abogado tiene esa obligación en casos civiles, pero con "importantes reservas". 52 El mismo estudio subraya también que los "principios de ética jurídica algunas veces contradicen los principios comúnmente aceptados de moralidad cívica". ${ }^{53}$ Probablemente esto es particularmente cierto respecto de la obligación de decir la verdad: la moralidad cívica está quizás a favor de que la gente diga la verdad, pero pareciera que no existe una obligación de decir la verdad -y menos de decir "toda la verdad”- cuando se trata de abogados. A lo más ellos pueden estar obligados a no usar elementos de prueba o aserciones de otras personas que saben que son falsas, pero esto no es equivalente a decir que tienen un deber ético de ser veraces. Como ha sido señalado en forma realista, "no se presume que el actor crea algo con respecto la demanda, y menos aún que crea que es verdadera". ${ }^{54}$ Esto se confirma, por ejemplo, si consideramos la Regla 11 de las Federal Rules of Civil Procedure estadounidenses. Esta regla ha sido modificada con el propósito de reforzar el rol y la responsabilidad de los

${ }^{47}$ Ver Twining, supra n. 6, p. 24.

${ }^{48}$ Id., supra n. 6, p. 288. En el mismo sentido ver Gewirtz, supra n. 26, p. 5.

${ }^{49}$ Id., supra n. 6, pp. 289, 290, 297, 305.

50 Ver e.g. Gewirtz, supra, n. 26, p. 9; Dershowitz, "Life is Not a Dramatic Narrative”, en Law's Stories, supra n. 5, p. 99. Acerca del bajo nivel de veracidad de las historias de los/as abogados/as ver también Coloma Correa, "Vamos a contar mentiras tralará... O de límites a los dichos de los abogados", en Rev. de Derecho, Universidad Austral de Chile, XIX, n. 2, 2006, p. 41.

${ }^{51}$ La pregunta es hecha e.g. por Gewirtz, supra n. 26, p. 9.

52 Ver Hazard-Dondi, Legal Ethics. A Comparative Study, Stanford, 2004, p. 114 y nota al pie. 2, p. 327.

Las "calificaciones" de la supuesta obligación de verdad del abogado en casos civiles no son especificadas.

53 Ver Hazard-Dondi, supra n. 52, p. 114.

${ }^{54}$ Ver Amsterdam-Bruner, supra n. 46, p. 174. 
abogados, pero no contempla ninguna obligación clara y explícita respecto de la veracidad de lo que los abogados dicen: sólo están obligados a constatar que de acuerdo a su mejor "conocimiento, información y convicción, formados después de una investigación razonable de acuerdo a las circunstancias", que "las alegaciones y demás pretensiones relativas a los hechos tienen un respaldo en los elementos de prueba disponibles" o que "probablemente tendrían un respaldo en elementos de prueba si hubiera ocasión de proseguir la investigación”. ${ }^{55}$ Esta disposición está orientada claramente a sugerir que las alegaciones sobre los hechos deben ser hechas seriamente y con buena fe, pero no requiere que sean verídicas.

En otros sistemas se impone a los abogados una "obligación de sinceridad", que parece incluir también el deber de hacer afirmaciones verídicas. ${ }^{56} \mathrm{Un}$ ejemplo significativo lo ofrece ahora el sistema inglés, desde que la Regla 22.1 de las Civil Procedure Rules, dictadas en 1999, requiere que los contenidos fácticos de las pretensiones sean confirmados por una "declaración de verdad" jurada tanto de la parte como de su abogado, bajo pena de perjurio para el caso de que se haga un juramento falso. ${ }^{57}$ Una norma similar está contemplada por $§ 138$ n.1 del Zivilprozessordnung alemán, que dispone que las partes están obligadas a ser veraces en sus afirmaciones sobre los hechos del caso. ${ }^{58} \mathrm{Sin}$ embargo, disposiciones como éstas no existen en todas partes y, por el contrario, varios sistemas no incluyen ninguna norma concerniente a la obligación de veracidad de las partes y de sus abogados. Por otro lado, es muy dudoso que pueda hacerse efectiva esa clase de exigencia de sinceridad. ${ }^{59}$ Por lo tanto, parece razonable creer que generalmente -y solo con algunas pocas y limitadas excepciones- los abogados no están obligados a decir la verdad. Menos aun están obligados a evitar distorsiones, manipulaciones o vacíos en sus descripciones de hechos.

La segunda pregunta puede ser planteada básicamente en estos términos: si las narrativas de los abogados son parciales, partidistas, manipuladas y engañosas, basadas sobre omisiones y mecanismos no racionales de persuasión, y por definición no verídicas, es difícil hacerlas calzar con la afirmación tradicional -ampliamente compartida en los sistemas de common law, y algo popular en sistemas de civil law también- de que el tribunal debe tomar su decisión solo escogiendo entre las dos historias en contienda, presentadas por las partes en un contexto de confrontación. ${ }^{60} \mathrm{Si}$, como parece, ambas historias ofrecidas por los abogados de las partes son "malas historias", destinadas a engañar y desorientar a quienes juzgan sobre los hechos con el objeto de ganar al adversario, la situación del juez, que en cualquier caso tiene que optar por una de estas dos historias, esto es -digamos-, por la "menos mala”, es una situación difícil y desafortu-

55 Para referencias sobre las modificaciones a la Regla 11 y breves comentarios, ver Federal Rules of Civil Procedure. Abridged Edition as Amended to May 13, 2005, p. 50.

56 Ver Hazard-Dondi, supra n. 52, p. 234.

57 Ver Millar, Contempt of Court, Oxford 2000, p. 630.

58 Ver Murray-Sturner, German Civil Justice, Durham, NC, 2004, p. 159.

59 Ver Hazard-Dondi, supra n. 52, p. 237.

${ }^{60}$ Ver, por ejemplo, Gewirtz, supra n. 26, 6: Twining, supra n. 6., p. 295. 
nada. Desde esta perspectiva, la situación del juez en los sistemas procesales de tradición continental es un poco menos penosa, ya que normalmente puede y debe componer su propia historia de los hechos del caso cuando las historias contadas por ambas partes sean poco confiables.

Sea como sea, la tercera pregunta requiere algunos comentarios adicionales en relación a un par de aspectos interesantes de las historias que narran los abogados sobre los hechos del caso.

Primero que todo, debe considerarse que esas historias son construidas de distintas maneras en las diferentes tradiciones jurídicas. Los sistemas procesales de civil law se basan en las "alegaciones de hechos": esto significa que el primer escrito de la demandante en que se plantea la pretensión debe incluir una descripción específica, detallada y en lo posible completa de todos los hechos principales del caso. La ausencia de esa descripción se considera un defecto de la demanda; se admiten correcciones posteriores en forma limitada, pero la primera descripción es fundamental. ${ }^{61}$ Más aún, de acuerdo con la comúnmente aceptada Substantierungstheorie, la afirmación de los hechos principales, que representan la llamada causa petendi, define el objeto de la pretensión. Con el fin de entregar un cuadro completo de la situación fáctica del caso, y también con el fin de fijar un marco de referencia para la evaluar la admisibilidad de los elementos de prueba relevantes, normalmente también las circunstancias que "rodean" los hechos principales (es decir, los hechos lógicamente relevantes) son cuidadosamente descritas en el primer escrito. En estos sistemas, por lo tanto, el caso se inicia, desde el comienzo, con el relato del demandante, en el que se supone que los hechos son narrados en forma completa y detallada. En gran medida, las reglas son las mismas para el demandado: él puede refutar parcialmente o in toto la historia del demandante, pero, en cualquier caso, tiene que presentar su propio relato de los hechos relevantes, que puede ser la versión opuesta del relato del demandante o una versión completamente distinta de los hechos. Sin embargo, también la historia de la demandada tiene que estar basada en una alegación completa y detallada sobre los hechos relevantes.

Las cosas son diferentes en lo procesal, pero sustancialmente equivalentes, cuando se trata de sistemas en los que la demanda no contiene necesariamente una narración completa de los hechos (o sistemas de notice pleading), como ocurre en el caso de las Federal Rules of Civil Procedure de Estados Unidos. En un sistema como ese, los hechos son establecidos paso a paso, a través de la presentación de los elementos de prueba: entonces, solo al final de la etapa prejudicial las dos partes pueden delinear el cuadro de la situación fáctica que subyace al caso. ${ }^{62}$ Por decirlo de alguna forma, el esbozo y la composición de las historias de las partes resultan más extensos, más fragmentados y

${ }^{61}$ Ver, por ejemplo, $\$ 130$ n. 3 del Zivilprozessordnung alemán; arts. 6 y 62 del Code de procedure civile francés; art. 399 n. 3 de la Ley de enjuiciamiento civil española, y art. 163 n. 4. del Codice di procedura civile italiano.

${ }^{62}$ Sobre este muy conocido aspecto del procedimiento federal estadounidense ver e.g. James-HazardLeubsdorf, Civil Procedure, 4th ed., Boston-Toronto-London, 1992, p. 145; Friedenthal-Kane-Miller, Civil Procedure, St. Paul, Minn., 1985, p. 252. 
más complicados que en los sistemas procesales de civil law. De hecho, en esos sistemas los hechos solo son investigados y analizados por los abogados antes de empezar el caso con el fin de chequear previamente si la pretensión puede tener sustento en una historia completa y detallada de los hechos. Si el resultado de este control previo es negativo, probablemente sería mejor para el demandante evitar iniciar un proceso. En todo caso, incluso en los sistemas de notice pleading llega el momento en que se espera que ambas partes presenten sus propias historias del caso.

Esas "historias" comparten típicamente algunas características que merecen atención.

Antes que nada, pretenden ser verdaderas. No son simples conversaciones entre los abogados y el tribunal: cuando un abogado alega algunos hechos, implícita o explícitamente sostiene que esos hechos son verdaderos. De hecho, sería un sinsentido que el abogado invocara el hecho material en que se basa su pretensión pero al mismo tiempo dijera o sugiriera que la afirmación relativa a ese hecho es falsa. Lo mismo ocurriría si llamo a mi esposa y le digo que mi vuelo desde Nueva York está con cinco horas de atraso, pero al mismo tiempo le digo que eso es falso: seguramente mi esposa se preguntará cuántos gin con tónica he bebido.

Entonces, una "pretensión de verdad" es típica de las narraciones de los abogados, así como de muchos otros relatos, independientemente de si ellas son efectivamente verdaderas o falsas. Pero como, respecto de una enunciación, una pretensión de verdad no es equivalente a ser verdadera, la historia de un abogado acerca de un hecho material no es más que una historia hipotética relativa a ese hecho. Esta hipótesis se presenta "como verdadera”, pero todavía no es más que una hipótesis: si es verdadera o falsa se determinará más adelante, en el curso del procedimiento y en la sentencia final. En términos de la teoría de los actos de habla esas narraciones pertenecen a la categoría de los actos ilocucionarios, con un objetivo ilocucionario asertivo. En efecto, ellas son aserciones, es decir, enunciados que pretenden afirmar una proposición verídica describiendo un hecho "con una dirección de ajuste palabra-mundo". ${ }^{63}$ En el caso de las historias contadas por las partes, hay otros dos aspectos importantes respecto de la función que cumplen: uno está conectado con el hecho de que el propósito del abogado es ganar el caso y, por lo tanto, la historia que cuenta está construida con el fin de persuadir a quien juzga los hechos de que su cliente merece ganar. ${ }^{64}$ Desde esta perspectiva, la narración del abogado tiene también otro objetivo ilocucionario, que es directivo, dirigido a sustentar una petición que puede ser concedida o negada. ${ }^{65} \mathrm{El}$ otro aspecto, no considerado por la teoría del story-telling, pero jurídicamente relevante, está relacionado con la carga de la prueba. En realidad, el abogado no cuenta su historia hipotética de los hechos del caso solo con el

${ }^{63}$ Sobre la función ilocucionaria de los actos del habla ver Searle, Mind, language and society. Philosophy in the real world, New York 1999, pp. 137, 140, 148; Id., Speech Acts. An Essay in the Philosophy of Language, Cambridge, 1980, pp. 23, 29, 65.

${ }^{64}$ Ver Amsterdam-Bruner, supra n. 46, pp. 174, 175.

${ }^{65}$ Sobre el concepto de objetivo ilocucionario directivo (illocutionary directive point), ver Searle, Mind, supra n. 63, p. 148. 
fin de informar al tribunal y a las otras partes. Cuando presenta la historia, el abogado toma sobre sus hombros la carga de la prueba en relación a esos hechos. A menos que existan presunciones legales aplicables al caso, y a menos que el tribunal establezca una distribución diferente de las cargas probatorias entre las partes, el principio básico es que el onus probandi incumbit ei qui dicit: quien afirma que un hecho es verdadero tiene la carga de probar la verdad de sus afirmaciones. Esto es generalmente válido en muchas áreas de la experiencia: en el contexto judicial significa que para ganar un caso, es necesario que se satisfaga la carga de la prueba que fue asumida al alegar los hechos. ${ }^{66}$

b) Testigos. En cierto sentido, un testigo es típicamente un story-teller. Es una persona que se supone que tiene conocimiento de algunos hechos del caso y de la que se espera que "relate la historia" de los hechos que conoce. Un testigo puede cumplir con su función narrativa de diferentes maneras: algunas veces se le pide narrar lo que sabe en forma ininterrumpida; más frecuentemente es interrogado -por los abogados de las partes o por el tribunal, o por ambos, dependiendo de las reglas sobre formación de esa clase de prueba- por medio de una o más series de preguntas específicas. En ese caso, la historia del testigo va apareciendo a través del transcurso de las respuestas que da. No existe un texto espontáneo y continuo: la historia está fragmentada y el testigo normalmente entrega pequeñas piezas dispersas de un mosaico ${ }^{67}$ que deben ser combinadas en un diseño general. Frecuentemente el hecho es descrito en la pregunta, y la respuesta del testigo es simplemente "sî" o "no”. Más aún, la estructura de este tipo de diálogo puede ser diferente: en la mayor parte de los sistemas de civil law el examinador es el juez, quien normalmente hace a los testigos preguntas sobre los hechos que fueron previamente señalados por las partes; en sistemas que adoptan la técnica del interrogatorio directo y el contrainterrogatorio, quienes interrogan son los abogados y la interrogación puede estar estructurada en dos o más etapas, en la cuales hacen sus preguntas en la secuencia que consideran más eficiente con el fin de obtener el testimonio. No obstante esta forma dialógica e interactiva de interrogación y de la variedad de formas en que esta puede ser conducida, puede asumirse que la historia es contada por el testigo y que esa historia puede ser reconstruida a partir del registro de la interrogación del testigo.

La historia que es contada por un testigo tiene dos aspectos relevantes que vale la pena destacar aquí. Tiene una fuerte pretensión de veracidad, mucho más fuerte que la pretensión de veracidad que -como hemos visto más arriba- es característica de las historias de los abogados. Mientras que el abogado no está bajo una real obligación de decir la verdad,

${ }^{66}$ El tópico de la carga de la evidencia no puede ser discutido adecuadamente aquí. Ver, en general, Gaskins, Burden of proof in Modern Discourse, New Haven-London, 1992. El problema es particularmente complejo porque en muchos casos la ley o el tribunal cambian la carga de probar un hecho desde la parte que originalmente lo alegó a la otra parte. Ver, por ejemplo, Gaskins, ibídem, p. 103; Conway-Jones, "Factual Causation in Toxic Tort Litigation: A philosophical View of Proof and Certainty in Uncertain Disciplines", en 35 Un.Richm.L.Rev. 2002, p. 875; "Allocating the Burden of Proof", en 72 Ind.L.J. 1997, "Discrimination Cases”, en 88 Mass. L. Rev. 2003, p. 48. Para un análisis crítico de esta práctica muy común ver García Grande, "Inaplicabilidad de las cargas probatorias dinámicas", en La Ley 11.05.05, 1.

${ }^{67}$ Ver Gewirtz, supra n. 26, p. 7; Burns, supra n. 6, p. 2. 
el testigo sí tiene esa obligación: jura decir la verdad, toda la verdad y nada más que la verdad, y el perjurio es penado por el derecho criminal. Esto no significa, por supuesto, que los testigos nunca mientan, pero significa que hay por lo menos una pretensión prima facie a favor de la veracidad de sus narraciones. Hay, sin embargo, un aspecto que puede resultar desconcertante, al menos en algunos sistemas. En los sistemas procesales de civil law los testigos son normalmente nombrados por las partes; solo algunas veces el tribunal tiene la facultad de llamar testigos de oficio. ${ }^{68}$ En ambos casos, sin embargo, se espera que el testigo sea imparcial, porque su papel es contar al tribunal una historia confiable acerca de los hechos que se supone que conoce. El testigo no está orientado hacia la parte, y la historia que cuenta se supone que es la "verdadera" historia de los hechos. En el sistema estadounidense los testigos también son presentados por las partes (porque los tribunales rara vez usan la facultad que les entrega la Regla 614 (a) de las Federal Rules of Evidence), pero están básicamente orientados hacia la parte, habiendo sido escogidos y previamente instruidos y preparados por "su" parte. Se espera de ellos, entonces $-\mathrm{y}$ es lo que requiere su juramento- que digan la verdad que fundamenta la posición de "su" parte en el caso. Si no lo hacen, se transforman en testigos "adversos" y son examinados como tales; pero incluso en este caso no se supone que sean neutrales e imparciales: siempre se asume que están orientados hacia la parte, en una forma positiva o negativa, y no hacia el tribunal. Puede haber una difícil tensión entre la obligación de decir la verdad y la inclinación de contar la historia que es preferida por la parte que presenta al testigo.

Por otro lado -y este es el segundo aspecto relevante-, normalmente la interrogación de un testigo incluye preguntas que están específicamente dirigidas a confirmar y confrontar su credibilidad. Sucede en los sistemas de tradición continental, ya que el juez, y también en alguna medida las partes, pueden hacer preguntas acerca de la credibilidad del testigo como persona y de la confiabilidad de su recuerdo y su narración de los hechos. Sucede -probablemente en una forma más efectiva- en los sistemas de common law ya que la contrainterrogación está típicamente dirigida a atacar y posiblemente a destruir la credibilidad del testigo y la confiabilidad de las respuestas que da durante el interrogatorio. En este sentido, uno bien puede entender el muy conocido dictum de Wigmore según el cual la contrainterrogación "es, más allá de toda duda, el mejor motor jurídico que se haya inventado para descubrir la verdad". ${ }^{69}$ Por supuesto, aquí estamos considerando lo que podría ser definido como el funcionamiento "fisiológico" de la contrainterrogación; una pregunta completamente distinta surge cuando los abogados abusan de este mecanismo con el fin de esconder o distorsionar la verdad y tratan de destruir al testigo independientemente de que haya o no dicho la verdad. ${ }^{70}$

${ }^{68}$ Ver Taruffo, "Poteri probatori delle parti e del giudice in Europa", en Le prove nel processo civile, Milano, 2007, p. 53.

${ }^{69}$ Ver Wigmore, supra n. 30, vol. V, rev.3rd ed., Boston-Toronto 1974, p. 32.

${ }^{70}$ Ver, por ejemplo, Freedman, "Professional Responsibility of the Criminal Defense Lawyer: The Three Hardest Questions”, en 64 Mich. L. Rev. 1966, p. 1474: donde se dice que el buen abogado usará la contrainterrogación con el propósito de "destruir" al testigo adverso, especialmente cuando el abogado sabe 
Este es exactamente el punto: la interrogación de un testigo es -o debe ser- realizada precisamente con el fin de investigar la verdad sobre lo que el testigo conoce acerca de los hechos del caso. No se espera que el testigo cuente una historia cualquiera para el entretenimiento del tribunal, de los abogados o del público. Se espera -y se le obliga- a presentar una narración verdadera de los hechos del caso. Esta narración, al estar compuesta de enunciados que describen hechos, también pertenece a la categoría de actos ilocucionarios asertivos y tiene la función de entregar a quien juzga los hechos una información verdadera y confiable.

c) Quien juzga los hechos (trier of fact). Quien juzga los hechos es el narrador final y por eso el más importante. Al término del procedimiento se enfrenta con un grupo de historias que han sido relatadas por los abogados y por los testigos: esas historias están normalmente en conflicto y competencia, o pueden ser simplemente diferentes y presentar varias narraciones de los hechos involucrados. La función principal de quien juzga los hechos es determinar cuál de todas es la "mejor" narrativa de los hechos en términos relativos, ya sea escogiendo una historia entre aquellas que fueron ya contadas o construyendo su propia historia si está autorizado para hacerlo y no está satisfecho con ninguna de las historias contadas por las partes. La narración que es presentada por quien juzga los hechos al final del juicio, en su decisión final, tiene al menos tres características relevantes: a) también es un acto ilocucionario asertivo, pues está compuesto por un conjunto de enunciados que describen hechos; b) es neutral y supra partes: el juez no tiene un propósito particular que alcanzar, excepto aquel de entregar una decisión cuidada y justa. No tiene un interés personal específico que avanzar ni personas a quien proteger o apoyar. No debe ser parcial a favor o en contra de nadie: se requiere que sea independiente e imparcial. Su perspectiva típica es, dicho en términos de Norbert Elias, aquella del desapego: su historia es y debe ser "desapegada" de la disputa de las partes sobre los hechos del caso. ${ }^{71}$ La función de su historia es solamente establecer que se ha determinado que ciertos hechos han sido confirmados en forma "objetiva"; c) por último, esa historia es verdadera, no solamente en el sentido de que tiene la pretensión de veracidad, sino porque es verdadera sobre la base del fundamento ofrecido por los elementos de prueba aportados y valorados. En un contexto judicial una aserción relativa a un hecho es verdadera en la medida que ha sido confirmada por pruebas: "verdadera" es equivalente a "probada". ${ }^{72}$ Entonces la narración final creada por quien juzga los hechos es verdadera si ha sido probada como verdadera.

que el testigo ha dicho la verdad. Ver también Ehrlich, The Lost Art of Cross-Examination, New York, 1970, p. 18; Appleman, Cross-Examination, Fairfax, Virg., 1965, p. 6.

${ }^{71}$ En otro lugar yo desarrollo el tema del desapego del juez en contraste con el involucramiento del abogado en el contexto de la prueba. Ver Taruffo, "Involvement and Detachment in the Presentation of Evidence”, en The Eyes of Justice, ed. By R. Kevelson, New York, a.o., 1993, p. 267.

${ }^{72}$ Ver, por ejemplo, Ferrer Beltrán, Prueba y Verdad en el Derecho, Madrid-Barcelona, 2002, p. 61: Coloma Correa, supra n. 24, pp. 35, 50, 143. 
Sin embargo, hay que hacer una distinción entre el caso en que los hechos son juzgados por un jurado y el caso en que -como sucede en los sistemas de civil law y en Inglaterra- quien juzga los hechos es un juez (o un tribunal colegiado). Gran parte del discurso sobre story-telling se ha construido con referencia a jurados, ${ }^{73}$ pero -irónicamente- los jurados en realidad no narran historias en absoluto: un veredicto no está nunca acompañado o sustentado por una motivación o ninguna otra manifestación escrita u oral que explique o justifique la decisión dada sobre los hechos de que se trata. Por lo tanto, a lo más podemos adivinar qué historias de los hechos construyeron los jurados en sus mentes y discutieron en el secreto de la sala del jurado, pero en realidad no podemos aprender nada acerca de dichas historias. De hecho, debemos trabajar con imaginación, o algo más. Esa imaginación puede estar más o menos sustentada por alguna prueba indirecta o inferencial, pero no podemos leer o escuchar las historias de los jurados, y nunca sabremos directamente cómo un miembro del jurado o el total del jurado construyó una o más narraciones sobre los hechos del caso. En consecuencia, nunca sabremos si el jurado escogió una de las historias contadas por los abogados de las partes o elaboró una reconstrucción autónoma y original de los hechos del caso.

Las cosas son muy distintas en el caso de los jueces continentales. Ellos tienen la obligación legal, frecuentemente reforzada por disposiciones constitucionales, de ofrecer una motivación en la que la decisión sobre la quaestio iuris tiene que estar sustentada por argumentos jurídicos adecuados y las conclusiones sobre los hechos deben estar lógicamente fundadas en las pruebas relevantes presentadas en el curso del procedimiento. Hay, por lo tanto, una narración de los hechos del caso que representa la manera en que son establecidos por el tribunal. Esa narración puede ser equivalente en parte o in toto a la narración presentada por una de las partes, en la medida que esa parte haya sido exitosa en probar "sus" hechos. Pero cuando el tribunal considera que ninguna de las historias ofrecidas por las partes ha sido sustentada por pruebas adecuadas, articulará una historia diferente basada en una reconstrucción autónoma y original de los hechos del caso, que tendrá que estar fundada en las pruebas que el tribunal ha tomado en consideración. Si las pruebas disponibles no son suficientes a la luz del estándar que la ley exige para una decisión "positiva” sobre los hechos, el tribunal va a contar una historia "negativa", diciendo que los hechos relevantes del caso no fueron establecidos y que, en consecuencia, las afirmaciones relativas a esos hechos no pueden ser tomadas como verdaderas. En cualquier caso, en esos sistemas hay efectivamente un relato de los hechos que es contado por el tribunal: este relato puede ser analizado, criticado y comparado con las otras narraciones que fueron contadas en el contexto judicial.

\footnotetext{
${ }^{73}$ Ver infra, $§ 4$
} 


\section{Construyendo narraciones}

Un relato de hechos no es nunca, especialmente en los procedimientos judiciales, algo que se encuentre ya preparado o que caiga del cielo sobre el escritorio del abogado o en el estrado del juez. Sucede exactamente lo contrario: los relatos son construidos por sus autores, generalmente por medio de complejas y sofisticadas actividades creativas. Esta construcción no es solamente una descripción pasiva o abstracta y neutral de los hechos: como se ha dicho, las historias construyen los hechos que son narrados. ${ }^{74}$ En algún sentido, por lo tanto, la construcción de una historia por su autor es también la construcción de los hechos que el autor narra: el autor, en otras palabras, construye su versión de los hechos. Al construir su historia, en verdad el autor "da forma a la realidad". 75 Por estas razones, puede ser interesante considerar al menos algunos de los aspectos más importantes de la construcción de relatos, tomando prestados algunos conceptos generales desde la teoría narrativa, pero dirigiendo la atención a la construcción de narrativas judiciales. Desde esta perspectiva pueden distinguirse algunas "modalidades de construcción”, aunque ellas se combinan e interfieren unas con otras en la creación de cualquier narrativa de hechos.

a) Construcción de categorías. Como lo enfatizan Amsterdam y Bruner, las categorías son "omnipresentes e ineludibles en el uso de la mente humana", ${ }^{76}$ por cuanto son el principal mecanismo que las personas emplean al interpretar y organizar la realidad, asignando sentido y ubicando sucesos en un contexto particular de ideas, ${ }^{77} \mathrm{y}-$ por lo tanto- al construir narrativas. Existen muchas categorías: cambian de acuerdo al tiempo y el espacio y nunca están fijas en su forma y contenido; ${ }^{78}$ más aún, cada persona tiene sus propias categorías de acuerdo a su propia cultura. ${ }^{79}$ Como la construcción de narrativas se basa en la categorización, la consecuencia obvia es que cuando se usan diferentes categorías o cuando una categoría se usa en diferentes versiones o sentidos, se construyen diferentes narrativas. No hay necesidad de desarrollar aquí un análisis acabado del uso de categorías: ${ }^{80}$ unos pocos ejemplos pueden ser suficientes para mostrar cómo las narrativas pueden variar cuando se usan diferentes categorías.

Incluso confiando en el concepto más común de tiempo, y sin caer en las complejidades filosóficas acerca de la idea de tiempo o incluso en las ideas más sofisticadas de espacio-tiempo, está claro que una categorización distinta de tiempo crea diferencias significativas en la construcción de narrativas. Una cosa es decir, por ejemplo, que

\footnotetext{
${ }^{74}$ Ver Amsterdam-Bruner, supra n. 46, p. 111.

75 Ver Amsterdam-Bruner, supra n. 46, p. 135.

${ }^{76}$ Ibidem, p. 19.

77 Ver Amsterdam-Bruner, supra n. 46, 2 p. 8.

78 Ver Amsterdam-Bruner, supra n. 46, p. 37.

79 Ver Amsterdam-Bruner, supra n. 46, p. 27.

${ }^{80}$ Para tal análisis ver principalmente Amsterdam-Bruner, supra n. 46, p. 19. Ver también los ejemplos ampliamente analizados ibídem, at 55 .
} 
el suceso S2 ocurrió un segundo o uno o cinco minutos después del suceso S1, y otra completamente diferente es decir que S2 ocurrió seis meses, un año o diez años después de S1. Estas serían historias completamente distintas en relación a S1 y S2. De manera similar, una cosa es decir que S1 y S2 ocurrieron en el mismo lugar, pero sería otra cosa decir que S2 ocurrió a un metro, una milla o a diez mil millas de S1. Una vez más, la variación de las distancias lleva a contar historias completamente diferentes.

Otro ejemplo interesante que se da frecuentemente en los contextos judiciales es aquel de la causalidad. La causalidad es una de las categorías que se usa con más frecuencia en el derecho ${ }^{81}$ así como en otras áreas de la experiencia y hace muchos siglos es objeto de debates filosóficos y científicos, los que naturalmente no pueden ser discutidos aquí. Desde la perspectiva de la construcción de narrativas, es probablemente más interesante considerar la causalidad como un "modelo mental" 82 o como un "modelo cognitivo idealizado", 83 esto es: como un marco psicológico que se usa comúnmente con el fin de dar forma a las conexiones entre los hechos. Con todo: si decimos que una acción realizada por A provocó un daño físico a $\mathrm{B}$, estamos hablando en términos de una causalidad directa y específica, porque estamos describiendo dos eventos particulares e individuales respecto de los cuales estamos diciendo que uno es la causa real, concreta e inmediata del otro. ${ }^{84}$ Pero si decimos que el evento E1 puede aumentar en cierta medida la probabilidad de eventos del tipo E2 en una población determinada, estamos hablando en términos de la llamada causalidad general, que es un concepto completamente distinto de causalidad y que -a lo más- puede ser expresado en términos de la probabilidad de E2 si ocurre E1. ${ }^{85}$ Las dos historias son muy distintas: la primera está correctamente fundada en la categoría de la causalidad, entendida como la conexión directa entre dos eventos, mientras que la última debiera ser más propiamente narrada en términos de probabilidad estadística. Contar esta última historia en términos de causalidad específica sería erróneo y engañoso, porque sugeriría la idea de una fuerte conexión única que realmente no existe; contar la primera historia en términos de probabilidad también sería engañoso porque sugeriría que hay solo una conexión probable en vez de una causalidad directa. Aún más, si eventos del tipo E1 y del tipo E2 ocurrieran en una población determinada, pero no se descubriera ninguna relación ulterior entre ellos, significaría que la conexión entre ellos no puede ser descrita ni en términos de probabilidad, ni -mucho menos- en

${ }^{81}$ Ver, por ejemplo, el trabajo clásico de Hart y Honoré, Causation in Law, Oxford, 1959, y Stella, Leggi scientifiche e spiegazione causale nel diritto penale, Milano, 1990.

${ }^{82}$ Ver Johnson-Laird, “Causation, Mental Models and the Law”, en 65 Brookl.L.Rev., 1999, p. 67.

${ }^{83}$ Ver Winter, A Clearing in the Forest, Law, Life and Mind, Chicago-London, 2001, pp. 88, 93, 105.

${ }^{84}$ Sobre el concepto de causalidad específica o individual ver e.g. Taruffo, supra n. 40, p. 107: Stella, Giustizia e modernità. La protezione dell'innocente e la tutela delle vittime, III ed., Milano, 2003, p. 339: GreenFreeman-Gordis, Reference Guide on Epidemiology, en Reference Manual on Scientific Evidence, Federal Judicial Center, 2000, p. 381.

${ }^{85}$ Sobre el concepto de causalidad general, ver Taruffo, ibídem; Stella, supra n. 84, p. 291; GreenFreeman-Gordis, supra n. 84, pp. 374, 383. 
términos de causalidad: ${ }^{86}$ esa descripción distorsionaría el significado de la información que provee la ciencia y por lo tanto sería falsa.

Si uno combina todas las variedades posibles de tiempo, espacio, causalidad y conexiones no causales, el resultado claro es que existe un gran número de narrativas posibles para describir la ocurrencia combinada de E1 y E2; algunas de ellas pueden ser más coherentes y plausibles que las otras; algunas de ellas pueden ser ciertas y algunas falsas. En todo caso, el diferente uso de categorías no puede sino producir diferentes historias.

b) Construcción lingüística, semántica y lógica. Obviamente la calidad de la narración depende del uso correcto del lenguaje en que esta se relate: una historia mal escrita, salpicada de errores de gramática y sintaxis, puede incluso ser imposible de entender. Igualmente obvio es el requisito de corrección semántica: usar las palabras en su sentido correcto y propio y evitar el cambio de sentido del mismo término durante el curso de la narración son reglas elementales que no requieren mayor análisis. Lo mismo puede decirse de las reglas de la coherencia lógica, como aquellas de acuerdo a las cuales el narrador debe evitar contradicciones, saltos en la línea argumental y en la descripción de los eventos conexos, como también el uso de inferencias injustificables. Si consideramos un texto de literatura experimental, puede que algunas o todas de estas reglas sean dejadas de lado, pero ellas deben ser seguidas en un texto que pretende ser la narración descriptiva de un evento o un conjunto de eventos.

Hay, sin embargo, un aspecto de la construcción lingüística y semántica que requiere algunos comentarios adicionales. Twining destaca cómo las historias generalmente disuelven la distinción entre hecho y valor, ${ }^{87}$ pero este es un asunto especialmente importante en relación a la construcción de las narrativas judiciales. De acuerdo con la gran distinción de Hume, los enunciados que describen hechos deben ser cuidadosamente separados de los juicios de valor y ninguno puede ser derivado del otro. Esa distinción es ineludible, no solo por razones filosóficas, aunque puede ser difícil de aplicar en la práctica porque el derecho frecuentemente define los supuestos de hecho a través de términos valorativos ${ }^{88} \mathrm{y}$ porque frecuentemente la gente común no entiende la diferencia entre hecho y valor. No obstante, siempre tiene que tomarse en consideración que los enunciados descriptivos son apofánticos, esto es, verdaderos o falsos: por lo tanto, ellos pueden ser probados ya sea como verdaderos o como falsos. Los enunciados que expresan juicios de valor no son apofánticos: ellos pueden ser fundamentados y justificados, o criticados y rechazados, pero no puede ser probada su verdad o falsedad. En términos jurídicos y judiciales esto significa que solo los

${ }^{86}$ Sobre el concepto de mera conexión, ver Kaye-Freeman, "Reference Guide on Statistics", en Reference Manual, supra n. 84, p. 91: Fubinfeld, Reference Guide on Multiple Regresion, ibidem, pp. 183, 185; GreenFreeman-Gordis, supra n. 84, p. 336.

${ }^{87}$ Ver Twining, supra n. 6, pp. 312, 335, 336.

${ }^{88}$ Discuto más ampliamente este tema en otra parte: ver Taruffo, supra n. 24, p. 105: Id., "Value Judgments in the Judgement of Fact", en Archivum Juridicum Cracoviense, XVI, 1985, p. 45. Ver también Wróblewski, Facts in Law, en Id., Meaning and Truth in Judicial Decision, $2^{\text {nd }}$ ed., Helsinki 1983, p. 108. 
enunciados que describen hechos, es decir, solo las partes fácticas de una narración, pueden ser probados o no probados, mientras que las afirmaciones de valor, es decir, los aspectos valorativos de una historia, no pueden ser probadas o no probadas. Por ejemplo: una cosa es afirmar que la velocidad de un auto era "excesiva" y una cosa diferente es afirmar que ésta "excedió el límite de 65 millas por hora”. La última afirmación es "fáctica” y puede ser verificada objetivamente (por un velocímetro), mientras que la primera afirmación expresa una evaluación puramente subjetiva que puede ser compartida posiblemente por varias personas pero que no puede ser objetivamente probada. La última afirmación es materia de prueba; la primera es un asunto de apreciación. ${ }^{89}$

En la medida que una narración pretende ser verdadera, merece ser tomada como verdadera o tiene que ser considerada como verdadera porque está respaldada por pruebas suficientes, la diferencia entre enunciados descriptivos y enunciados valorativos se da obviamente por supuesta. Esa diferencia es importante, en contextos judiciales, desde muchos puntos de vista: basta con decir que normalmente un testigo común (es decir, un testigo no experto) no puede expresar su propia valoración personal sobre los hechos que está narrando. En términos más generales, la relevancia de los elementos de prueba es establecida sobre la base de su capacidad de entregar información que confirme la verdad o falsedad de una afirmación, lo que implica que la prueba debe ser referida a los hechos, no a las valoraciones.

En consecuencia, contar una historia en términos valorativos en lugar de hacerlo en términos fácticos significa contar una historia diferente: una historia que no puede ser objeto de prueba.

c) Construcción social o institucional. Incluso si uno no comparte en toda su extensión el ataque crítico de Ian Hacking contra la pretendida "construcción social” de todo, ${ }^{90}$ uno tiene que reconocer que en diversas situaciones, tanto en la vida diaria como en contextos judiciales, nos manejamos con hechos materiales. Un accidente de tránsito, una lesión o la muerte de una persona son hechos materiales "brutos" antes y además de ser los fundamentos jurídicos para una demanda de indemnización de perjuicios y antes y además de ser "construidos" en alguna otra forma. ${ }^{91}$ Sin embargo, en muchos casos los hechos de la experiencia cotidiana, y particularmente los hechos involucrados en el proceso judicial, son "institucionales" o "socialmente construidos" 92 aunque están frecuentemente basados sobre algunos hechos "brutos” que preceden lógicamente a

${ }^{89}$ Una velocidad de 20 millas por hora puede ser considerada excesiva por alguien, bajo circunstancias determinadas, incluso cuando el límite es de 65 millas por hora.

90 Ver Hacking, The Social Construction of What?, Cambridge, Mass.-London, 1999.

${ }^{91}$ Para una discusión crítica de las teorías que señalan que los hechos son solamente construcciones sociales, ver Hacking, ibídem, 23, p. 80.

92 En general, sobre la distinción entre hechos "brutos" e "institucionales" ver Searle, La costruzione della realtà sociale, it.tr, Milano, 1996, 36; MacCormick-Weinberger, An Institucional Theory of Law. New Approaches to Legal Positivism, Dordrecht, 1986. Para una teoría general de los hechos institucionales, ver nuevamente Searle, ibidem, p. 130. 
su calificación institucional. ${ }^{93}$ En el conocido ejemplo de Searle, un pedazo de papel con impresiones verdes es un billete de $\$ 100$ no por su realidad material, sino por las convenciones sociales, legales, institucionales y organizacionales en virtud de las cuales "cuenta como" un billete de \$100. ${ }^{94}$ Los mismos comentarios pueden hacerse acerca de muchos "hechos" que son relevantes en casos judiciales: por ejemplo, si pensamos en la transferencia de los llamados "productos financieros", o en transacciones virtuales en comercio internacional, estamos pensando en "hechos" que pueden tener relevancia jurídica $-y$ por lo tanto deben ser establecidos en el tribunal- pero que tienen una base empírica muy frágil, si tienen alguna. En esas situaciones, describir y narrar un hecho necesariamente requiere determinar también las dimensiones sociales e institucionales del hecho, incluso yendo más allá de su materialidad empírica.

d) Construcción cultural. En un sentido general, la construcción de narraciones siempre es "cultural" en sí misma: las categorías, el lenguaje y las construcciones sociales son parte de la cultura de cada story-teller. Hay, sin embargo, un sentido más específico en el cual la construcción de narrativas es cultural: esto sucede porque cualquier narrativa se sustenta en una cultura y es creada por medio de una cultura, comprendida como un conocimiento del mundo. El concepto de coherencia narrativa puede ser definido, entonces, en términos de correspondencia de la historia relatada con los modelos de narraciones que existen dentro del "stock de conocimiento" que representa los contenidos de esa cultura. ${ }^{95}$ Como Twining subraya, los relatos hacen una referencia permanente al "stock de conocimiento" que proporciona el antecedente cultural de cada story-teller. ${ }^{96}$ En algún sentido, ese "stock de conocimiento" puede ser comprendido como un equivalente al "sentido común" o a la "cultura general". 97 En todo caso, es un "conjunto de cosas" extremadamente vago, indeterminado, variable e incierto. Es claramente imposible definirlo, básicamente por la vaguedad y variedad de su contenido; sin embargo, algunos aspectos de los "conocimientos" incluidos en el "stock" merecen algunos comentarios adicionales.

Primero que todo, uno debe enfatizar que dentro del cúmulo dispar de esos "conocimientos" hay muchas cosas que no son conocimiento en absoluto. De acuerdo con Twining, ese "stock" es una suma de "aglomeraciones de creencias mal definidas que típicamente consisten en un complejo potaje de información, modelos sofisticados, memorias anecdóticas, impresiones, relatos, mitos, proverbios, deseos, estereotipos, especulaciones y prejuicios, más o menos fundados". ${ }^{98}$ No consiste en "proposiciones individuales, empíricamente probadas y ya articuladas". 99

\footnotetext{
93 Sobre la precedencia lógica de los "hechos brutos" ver Searle, supra n. 92, pp. 67, 138.

${ }^{94}$ Ver Searle, supra n. 92, pp. 38, 41, 47, 93.

95 Para esa definición, ver Jackson, supra n. 6, p. 59.

96 Ver Twining, supra n. 6, pp. 310, 335, 338, 443.

97 Discuto estas nociones en otra parte. Ver Taruffo, "Senso comune, esperienza e scienza nel ragionamento del giudice”, en Id., Sui confini, Scritti sulla giustizia civile, Bologna, 2002, p. 121.

98 Ver Twining, supra n. 6, p. 338.

99 Ver Twining, ibidem.
} 
Dentro de este "potaje”, algunos ingredientes merecen una atención especial. Primero que todo: los prejuicios. El sentido común está lleno de prejuicios de género, raciales, religiosos, étnicos e incluso profesionales que, de acuerdo a Schauer, son creencias infundadas respecto de una persona, normalmente basada en generalizaciones estadísticamente febles. ${ }^{100}$ Ellas pueden afectar profundamente la construcción de narrativas y son particularmente peligrosas porque pueden ser efectivas en hacer la historia especialmente coherente y creíble para aquellos que comparten los mismos prejuicios. De esta manera los hechos pueden ser distorsionados y manipulados sustancialmente, pero la historia relatada puede sonar muy persuasiva para una audiencia similarmente prejuiciada. ${ }^{101}$

El "potaje" también está hecho de libretos (scripts). Estos "encarnan las expectativas y las prácticas corrientes en una cultura: ellos capturan las formas corrientes en que la gente vive y se espera que viva su vida cotidiana". 102 "Mucho de nuestro conocimiento básico de la cultura está organizado en términos de esos libretos": ellos están frecuentemente ocultos en las narraciones y son "normalmente tácitos en lugar de explícitos". ${ }^{103}$ Los libretos, por lo tanto, encarnan las ideas de la "normalidad" existente en una determinada cultura: se usan para articular los hechos de acuerdo a secuencias normales de sucesos o comportamientos. Una vez más, se trata de un mecanismo que puede ser muy efectivo en la manipulación de los hechos: los hechos no son narrados "como ellos ocurrieron"; ellos son "reducidos a la normalidad" porque de esa forma pueden sonar más familiares para un público que comparte las mismas ideas sobre lo que es normal y anormal. Esto no significa solamente que los sucesos sean encuadrados en una especie de trama predeterminada; ellos también son interpretados de acuerdo a un modelo predeterminado, y -como la referencia a la normalidad es prescriptiva más que descriptiva- ${ }^{104}$ tienen el efecto de transmitir una suerte de juicio moral: lo que es presentado como normal es bueno, y lo que es presentado como anormal es malo. En consecuencia, no se trata de un mecanismo para informar a la audiencia sobre la verdad de algo, sino de un mecanismo para condicionar las reacciones de la audiencia.

Otros ingredientes importantes son los estereotipos y los perfiles. ${ }^{105}$ Según Schauer, los estereotipos y perfiles usualmente se refieren a personas, como la "esposa leal" y el "marido infiel”, "el policía corrupto”, el "chofer negro"106 y el "violador afroamericano", el "asiático" y el "traficante de drogas latinoamericano", ${ }^{107}$ el "terrorista islámico", 108

100 Ver Schauer, Profiles, Probabilities and Stereotypes, Cambridge, Mass-London 2003, p. 15.

101 Ver Menashe-Shamash, supra n. 21, p. 11.

102 Para esa definición ver Amsterdam-Bruner, supra n. 46, p. 121. Ver también Menashe-Shamash, supra n. 21, p. 13.

103 Ver Amsterdam-Bruner, ibídem.

104 Ver principalmente Hacking, supra n. 24, pp. 160, 163.

${ }^{105}$ Los dos ingredientes pueden ser discutidos juntos porque pueden ser considerados como las dos caras de un mismo fenómeno: en realidad, la actividad llamada "profiling" puede terminar en producir perfiles y estereotipos. Acerca de estos temas ver principalmente Schauer, supra n. 100, pp. 138, 155.

106 Ver Schauer, supra n. 100, p. 191.

107 Ver Schauer, supra n. 100, p. 167.

108 Ver Schauer, supra n. 100, p. 181. 
etcétera. Los estereotipos y los perfiles están normalmente basados en generalizaciones burdas y por lo tanto tienen múltiples defectos. Algunas veces las generalizaciones en que se fundan los estereotipos y perfiles están justificadas, y por lo tanto pueden ser útiles -al menos en alguna medida- para orientar decisiones y juicios. ${ }^{109}$ De la misma forma, esos estereotipos y perfiles pueden ser usados apropiadamente en la construcción de narrativas. En muchos casos, sin embargo, y quizás en la mayoría de los casos -especialmente aquellos que involucran raza, género y orientación sexual-, los estereotipos están típicamente basados en generalizaciones estadísticas infundadas, ${ }^{110}$ y por lo tanto no reflejan ninguna realidad específica. En realidad, no están destinados a dar una imagen precisa de personas particulares: son usados como medios para subsumir personas o comportamientos específicos bajo "tipos" bien conocidos, esto es, como un mecanismo que reduce la especificidad de tales personas o comportamientos, con el fin de simplificar la comprensión y la descripción de la realidad. En realidad, usar los estereotipos es solo una forma de aplicar una especie de lecho de Procusto, esto es, de estirar a las personas bajas y cortarles las piernas a las altas de manera de hacerlas calzar en un largo determinado. ${ }^{111}$ Cuando esto sucede, quien presenta los hechos incurre en la falacia narrativa, porque distorsiona los hechos para forzarlos a calzar dentro de una estructura narrativa culturalmente familiar. ${ }^{112}$ No es sorprendente que incluso la palabra "estereotipo" tenga una connotación negativa. ${ }^{113}$ Por lo tanto, en la medida que una narración se base en estereotipos, probablemente no podrá ser tomada como la descripción fiel de hechos reales: ella tiende a transformarse en una suerte de idealización en que caracteres típicos actúan en las formas típicas, como ocurre en la commedia dell'arte italiana.

Quizás los ingredientes más importantes y más desconcertantes del "potaje” son las generalizaciones de sentido común. Ellas son necesarias en cada etapa del razonamiento sobre la prueba y los hechos, ya que en la mayoría de los casos son las premisas para las inferencias que conectan la información y los hechos. Como dice David Schum, ellas son el "pegamento" del razonamiento inductivo. ${ }^{114}$ El problema es que el estatus epistémico de esas generalizaciones es usualmente vago e indeterminado: en realidad, pueden ser racionales e irracionales, buenas y malas, dependiendo de si tienen o no un sólido fundamento epistémico. ${ }^{115}$ En algunos pocos casos son una especie de vulgarización de las leyes científicas o de generalizaciones "verdaderas" que provienen de la ciencia: en esos casos -asumiendo que la traducción de la ciencia al sentido común no alteró o distorsionó el conocimiento científico original- son universales ${ }^{116}$ y pueden tener un grado significativo de confiabilidad; el caso típico, sin embargo, es aquel de las genera-

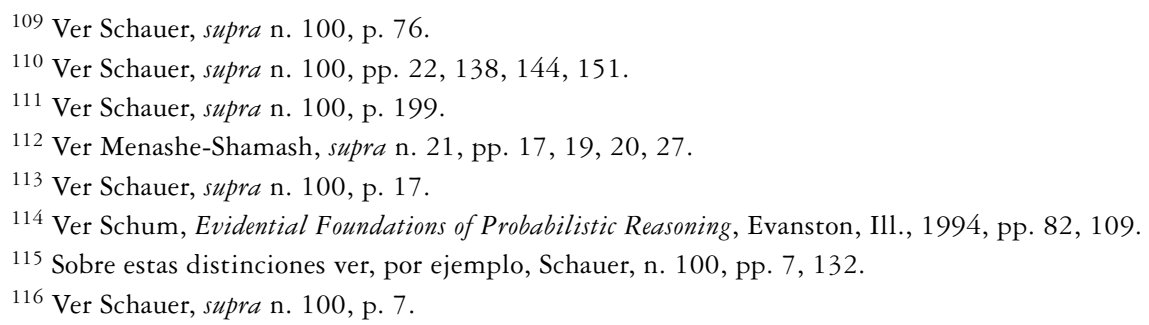


lizaciones que no son universales. ${ }^{117}$ Las generalizaciones no universales pueden tener una base estadística adecuada, y en ese caso pueden ser significativamente confiables: en la mayoría de los casos, sin embargo, no tienen fundamentos estadísticos confiables y están fundadas solamente en el sentido común. En otras palabras, son "generalizaciones espurias": 118 esto significa que son infundadas, que su sentido es vago, su generalidad es dudosa y que pueden ser contradichas por otras generalizaciones de sentido común o por una serie de circunstancias específicas. ${ }^{119}$

En algunas áreas de la cultura jurídica europea (especialmente en Alemania e Italia y en alguna medida en España) existe una tendencia a articular una noción de generalización de sentido común -con el objetivo de adscribirle un estatus epistémico menos vago- haciendo referencia a la "experiencia" que debe servirle de sustento. Originalmente este concepto fue definido por Friedrich Stein (un destacado académico alemán en el área del derecho procesal civil) en un pequeño libro publicado en 1893 dedicado al conocimiento personal del juez. ${ }^{120}$ La principal idea de Stein era que la experiencia podía llevar a la formulación de "máximas" (llamadas Verhandlungsmaximen) obtenidas por inducción a partir de un gran número de casos particulares, y dotadas entonces de cierta generalidad. Esas generalizaciones serían "reales" y basadas en la experiencia en lugar de basadas en la ciencia y la lógica. No obstante su debilidad teórica, ${ }^{121}$ el concepto de "máximas de la experiencia" de Stein todavía es bastante popular. Sin embargo, esa idea es más engañosa que útil: transmite la impresión de que una inferencia basada en una "máxima" es deductivamente válida porque es derivada de una premisa general, aunque en verdad la mayor parte de las máximas no son generales. Esa impresión se basa en una confusión entre generalidad y generalización en un contexto en que las generalizaciones son usualmente infundadas. En realidad, nadie sabe la experiencia de quién, por cuánto tiempo, de qué, de cuántos casos, recogida por quién, según qué parámetros es necesaria para poder afirmar que ha surgido una máxima. ${ }^{122} \mathrm{De}$ hecho, muchas máximas no están basadas en experiencias reales sino en prejuicios, libretos y estereotipos, y por lo tanto los mismos problemas ya señalados a propósito de ellos surgen también en el uso de las máximas.

Finalmente, otro ingrediente que es usado frecuentemente consiste en cuantificaciones estadísticas o probabilísticas infundadas o no verificables. Cuando las estadísticas se usan correctamente y las probabilidades (bayesianas o no bayesianas) están bien calculadas $^{123}$ no se presentan grandes problemas y los hechos pueden ser establecidos

117 Ver Schauer, supra n. 100, p. 9.

118 Sobre el concepto de generalizaciones espurias, ver Schauer, supra n. 100, p. 11.

119 Ver Twining, supra n. 6, p. 335.

${ }^{120}$ Ver Stein, Das private Wissen des Richters, Leipzig, 1893, p. 16.

${ }^{121}$ He discutido la razón de esa debilidad teológica en otra parte: ver Taruffo, supra n. 97, p. 140; Id., supra n. 24, p. 397.

122 Ver van Zandt, “An Alternative Theory of Practical Reason in Judicial Decisions”, en 65 Tul.L.Rev., 1991, p. 795; Taruffo, supra n. 97, p. 132.

${ }^{123}$ El uso de evidencia estadística y de probabilidades es un tema amplio y complejo que no puede ser discutido aquí. Ver, por ejemplo, Schum, supra n. 114; Faigman-Kaye-Saks-Sanders, Modern Scientific Evidence. The Law and Science of Expert Testimony, $2^{\text {nd }}$ ed., St. Paul, Minn. 2002, vol. 2: Manual for Complex 
por medio de inferencias válidas. Los problemas surgen cuando la gente, quizás en un esfuerzo por aparecer "científica", habla en términos de frecuencias y probabilidades, dando valores numéricos y porcentajes a todo, en una variedad de situaciones en que no hay disponibles cuantificaciones numéricas y frecuencias estadísticas confiables. Es bien conocido, especialmente después del análisis fundamental de Nisbett y Ross, ${ }^{124}$ que los seres humanos son normalmente incapaces de cuantificar sus experiencias correctamente: las probabilidades erróneas y las frecuencias inventadas están entre las fuentes más importantes y frecuentes de falacias heurísticas en el discurso común cotidiano. El mismo error se comete cuando una "máxima de experiencia" es presentada en términos estadísticos o probabilísticos ${ }^{125}$ (quizás vagamente, como "la mayoría de la gente hace esto y esto") sin ningún sustento para dicha cuantificación.

Por lo tanto, como destaca Twining, las generalizaciones de sentido común son necesarias, pero peligrosas. ${ }^{126}$ Una vez más, sin embargo, pueden ser más o menos peligrosas o no serlo en absoluto, dependiendo del tipo de narración y de la forma en que sean usadas. En una novela histórica uno puede referirse a la experiencia (de la gente que vivía en otra época) de que el sol rota alrededor de la tierra, pero sería más bien extraño referirse a la misma experiencia en una narración judicial actual. Los signos de brujería pueden ser descritos en una novela medieval, pero sería inusual hablar de ellos en una narración judicial moderna: la calificación de "moderna" es necesaria porque por muchos siglos, y en Estados Unidos al menos hasta 1693 con los juicios a las brujas de Salem, las narrativas judiciales estaban llenas de brujas, es decir, de personajes creados por la cultura de aquellos tiempos. ${ }^{127}$

En contextos judiciales el peligro inherente en el uso de generalizaciones de sentido común debe ser contrarrestado en la mayor medida posible. Por ejemplo, ellas no deben ser invocadas cuando son contradichas por la ciencia, por evidencia empírica específica o por pruebas disponibles en el caso concreto. Adicionalmente, una máxima de la experiencia tampoco debiera ser invocada cuando -como normalmente sucede- se contradice con otras máximas, o cuando no calza bien con los hechos particulares de que se trate. En general, además, las narrativas basadas en generalizaciones de sentido común deben estar "ancladas" en el terreno relativamente sólido del mejor conocimiento disponible en la cultura social a la que se hace referencia. ${ }^{128}$

Litigation, supra n. 39, pp. 341, 435; Reference Manual on Scientific Evidence, supra n. 84, pp. 183, 333: Probability and Inference in the Law of Evidence, The Uses and Limits of Bayesianim. Ed. por P. Tillers y E.D. Grenn, Dordrecht a.o. 1988: Frosini, Le prove statistiche nel processo penale e nel processo civile, Milano, 2002: Taruffo, supra n. 24, pp. 166, 196.

${ }^{124}$ Ver Nisbett-Ross, Human Inference. Strategies and Shortcomings of Social Judgement, Englewood Cliffs, NJ, 1980.

${ }^{125}$ Ver, por ejemplo, Koch-Rüssmann, Juristische Begründungslehre. Eine Einführung in Grundprobleme der Rechtswissenschaft, München, 1982, pp. 285, 308, 332.

126 Ver Twining, supra n. 6, p. 334.

127 Ver, por ejemplo, los casos cuidadosamente analizados por Hoffer, The Salem Wichcraft Trials. A Legal History, Lawrence, KA, 1997, y por Merlo, Streghe, Bologna, 2006.

${ }^{128}$ Ver Wagenaar-van Koppen-Crombag, Anchored Narratives, The Psychology of Criminal Evidence, Harvester, 1993, pp. 61, 73, 237. 
En suma, el "stock de conocimiento" que representa la base ineludible de la construcción cultural de narrativas tiene al menos tres aspectos que sugieren el uso de un cuidado extremo y preciso en la construcción y en la evaluación de las narrativas. Por supuesto ese cuidado se requiere en tanto suponemos que las narrativas judiciales deben estar dirigidas a describir sucesos reales: no se necesita ningún cuidado - por supuesto- y todos los comentarios anteriores sobre construcción de narraciones serían insignificantes, si estamos pensando en relatos literarios.

El primero de estos aspectos es que -como se dijo más arriba- gran parte del "conocimiento" incluido en el "stock" no es conocimiento en absoluto, a menos que se convenga en que los mitos, prejuicios y generalizaciones infundadas merecen ser consideradas "conocimiento." Tomar cualquier cosa que proviene del sentido común como una base narrativa válida puede ser útil para construir una ficción plausible, pero es un método difícilmente confiable para crear narrativas judiciales. La credibilidad de esas narraciones recae en su referencia a conocimiento válido. Por supuesto, un relativista epistémico podría señalar que un conocimiento es válido solo dentro de un determinado contexto cultural, pero la respuesta podría ser que, entonces, se trata de escoger el contexto cultural correcto. Si escogemos un contexto cultural en el que la brujería existe, es posible que luego nos encontremos lejos de la cultura occidental moderna, sobre todo si acabemos quemando brujas sobre la base de una decisión judicial.

El segundo aspecto relevante es que ese "stock" está lejos de ser un conjunto de conocimientos claros, bien ordenados y coherentes. Precisamente lo contrario: en ese "potaje" hay un número infinito de cosas que se contradicen entre ellas. Proverbios, mitos, y otras, nunca forman un conjunto coherente. En la inmensa bodega del conocimiento popular, uno puede encontrar lo que uno quiera. Esto significa que del mismo stock pueden ser sacados diferentes materiales para la construcción de un número indeterminado de historias diferentes e incluso contradictorias sobre los mismos hechos. Mucha de la indeterminación del stock proviene de sus cambios frecuentes, profundos y más o menos veloces a lo largo del tiempo. Probablemente poca gente comparte en la actualidad la creencia, que alguna vez fue común, sobre la forma plana de la Tierra o sobre la existencia y los hábitos de las brujas. Por suerte el estereotipo de los italianos comiendo solo pasta y pizza mientras cantan y tocan la mandolina está desapareciendo, al igual que el del chino bajo vendiendo corbatas en las calles. Incluso estereotipos que alguna vez fueron poderosos, como "Bush el Gran Comandante" o "Berlusconi el Gran Líder”, están siendo rápidamente borrados del paisaje político. Por otro lado, nuevos ingredientes del potaje cultural están entrando: basta con pensar en la Internet, la comida china, los celulares y otros. ${ }^{129}$

El tercer aspecto significativo es que pensar, incluso por un solo momento, en un stock de conocimiento es una abstracción absoluta. Desde siempre han existido muchas culturas diferentes y cada una tenía y todavía tiene su propio "stock" de conocimiento.

${ }^{129}$ En general, sobre este fenómeno, ver Friedman, The Horizontal Society, New Haven-London, 1999. 
Es cierto que en la "sociedad horizontal" 130 operan fuerzas poderosas que crean capas de una cultura más bien uniforme, pero también es cierto que muchas sociedades modernas son multiétnicas y por lo tanto multiculturales. Las diferentes culturas están vivas en el mismo lugar y al mismo momento, y cada una de ellas tiene sus propios valores, sus propias reglas, sus propios estereotipos, mitos y formas de conocimiento. En lugares como Londres o Nueva York, pero incluso en Manhattan o en muchas ciudades europeas, ningún sociólogo de la cultura serio sería capaz de identificar y describir un stock específico de conocimiento, ni identificaría solo una cultura. En realidad, uno debería pensar en un "stock de stocks de conocimiento" para imaginar la inmensa riqueza y variedad de lo que la sociedad moderna "conoce". ${ }^{131}$

\section{LAS PARTES Y EL TODO}

La conexión necesaria entre las partes (palabras, oraciones, párrafos) y el texto completo es un tema clásico de la teoría hermenéutica. El continuo pasaje dialéctico de las partes al texto completo y del texto completo a sus partes -el llamado círculo hermenéutico- es la dinámica fundamental de cualquier interpretación, como ha sido aclarado por Schleiermacher y más recientemente analizado en el clásico trabajo de Gadamer sobre Wabrheit und Methode. ${ }^{132}$ Los principios generales de la hermenéutica pueden obviamente ser aplicados también a la interpretación de narrativas jurídicas y particularmente judiciales. En consecuencia, el sentido de una parte de una narración puede ser determinado solo por referencia al texto completo del relato, y el sentido general de la narración puede ser interpretado solo por referencia a todas sus partes. Usando nuevamente la metáfora del mosaico, uno podría decir que el significado de una sola pieza de vidrio está determinado por su posición en el diseño completo, pero también que el significado del mosaico como un todo está determinado por los colores y las posiciones de las piezas individuales de vidrio.

Con algunas adaptaciones menores, lo que se dice sobre la interpretación de un texto puede también ser referido a la escritura de un texto. Un escritor sabe que el sentido de las partes individuales de su escritura depende de todo el texto, y que el sentido general del texto está determinado por sus partes. ${ }^{133}$ Estos comentarios más bien de sentido común pueden ser aplicados a las narrativas judiciales: la persona que crea una narración de los hechos pertinentes está juntando las diferentes partes de la historia dentro de un texto en que las piezas individuales (enunciados relativos a hechos específicos, acciones y circunstancias) toman un significado que está determinado también por el contexto

\footnotetext{
${ }^{130}$ Ver nuevamente Friedman, ibídem.

${ }^{131}$ Para un comentario similar, ver Twining, supra n. 6, p. 444.

132 Ver Gadamer, Wabreit und Methode, Tübingen, 1972, pp. 188, 194, 296.

133 En cualquier caso, la voluntad del autor y su interpretación del texto es irrelevante para el sentido del texto, que es determinado solo por la interpretación. El autor no es un intérprete privilegiado y su interpretación no es normativa. Ver Gadamer, supra n. 132, p. 196.
} 
de la historia completa, la que a su vez es una combinación ordenada y coherente de enunciados específicos. Como se dijo arriba, una narración se construye solo con el fin de "dar sentido" a una serie de fragmentos de discurso.

El tema de la "historia completa" es la base de la teoría bolista del story-telling que ha sido propuesta, en oposición a la aproximación analítica o atomista a los problemas de la prueba judicial, principalmente en el área de la sicología social y con referencia específica a la forma en que se supone que los jurados toman sus decisiones sobre los hechos del caso. Las investigaciones empíricas hechas principalmente por Bennett y Feldman ${ }^{134}$ y por Pennington y Hastie ${ }^{135}$ parecen sustentar la conclusión de que los jurados no se involucran en un análisis detallado de los hechos y de los elementos de prueba relativos a esos hechos, sino que típicamente recurren a relatos con el propósito de organizar los medios de prueba que son presentados en el juicio. ${ }^{136}$ Entonces los jurados llegan a sus conclusiones sobre los hechos mediante una evaluación de la plausibilidad de las stories "completas" acerca de los hechos ${ }^{137}$ sin llevar a cabo ningún razonamiento analítico sobre los hechos específicos o los elementos particulares de prueba. En otras palabras, los jurados estadounidenses determinan la "verdad" de los hechos de que se trata "principalmente mediante la construcción y comparación de stories más que evaluando críticamente los argumentos desde la prueba". ${ }^{138}$ También se ha dicho que eso no solo sucede, sino que es una buena y recomendable forma de tomar decisiones sobre los hechos. ${ }^{139}$

No vale la pena poner a prueba aquí el valor descriptivo de la teoría holista, que puede ser concedido: ${ }^{140}$ bien puede ser que los jurados se comporten precisamente en la forma que la teoría holística afirma. Esto no significa, sin embargo, que dicha teoría merezca ser tomada como un modelo prescriptivo para la toma de decisiones sobre los hechos, ni que pueda ser tomada como una suerte de teoría general del proceso de decisión judicial. ${ }^{141}$ Vale la pena hacer algunos comentarios adicionales desde ese punto de vista.

Por una parte, como se dijo arriba, las narraciones son necesarias e ineludibles como medios para poner hechos fragmentados y dispersos y piezas sueltas de prueba en un contexto ordenado y plausible. En una palabra: las stories son necesarias para interpretar la información disponible y para reconstituir la realidad a la cual se refieren. Entendida

${ }^{134}$ Ver Bennett-Feldman, Reconstructing Reality in the Courtroom, New Brunswick, 1981. Ver también Jackson, supra n. 6, p. 61.

135 Ver Pennington-Hastie, “A Cognitive Theory of Juror Decision Making: the Story Model”, en 13 Cardozo L.Rev. 1991, Making, ed. por R. Hastie, New York, 1993.

${ }^{136}$ Ver Twining, supra, n. 6, p. 368: Pardo, "Juridical Proof, Evidence and Pragmatic Meaning: Toward Evidentiary Holism”, en 95 Northw. L. Rev. 2000, p. 399.

137 Ver Twining, supra n. 6, p. 334: Menashe-Shamash, supra n. 21, p. 5.

138 Ver Twining, supra n. 6, p. 336.

139 Ver Abu Hareira, “An Early Holistic Conception of Judicial Fact-Finding”, en Jur. Rev., 1986, p. 79.

${ }^{140}$ Para una evaluación crítica ver Jackson, supra n. 6, pp. 65, 71.

${ }^{141}$ Para coherentes aproximaciones críticas ver Damaška, "Atomistic and Holistic Evaluation of Evidence: A Comparative View", in Comparative and Private International Law. Essays in Honor of J.H. Merryman, D.S. Clerk ed., Berlin 1990, p. 91: Taruffo, supra n. 24, p. 281. 
en este sentido débil la teoría holista puede ser aceptada, pero no agrega nada relevante a la teoría actual sobre la toma de decisiones judiciales: es obvio que el juzgador tiene que articular los hechos y la información aportada por los elementos de prueba en una serie de enunciados de ser posible coherentes. ${ }^{142}$

Sin embargo, la teoría holista es defendida por sus partidarios como un modelo en un sentido mucho más fuerte, de acuerdo al cual la decisión sobre los hechos debe ser concebida y tomada precisamente como una elección entre stories rivales tomadas "como un todo", es decir, dejando de lado cualquier examen atomista o analítico de los hechos y cualquier valoración individual de los elementos de prueba. ${ }^{143}$ En esta segunda versión, la teoría holista resulta altamente controvertible, especialmente cuando enfatiza que las stories son "imposibles de verificar en términos de la realidad de la situación” que representan, ${ }^{144}$ porque los jurados deciden solamente sobre la base de su plausibilidad y no de su veracidad. Una aproximación crítica a esta segunda versión resulta incluso más justificada si se considera que la story puede incluir "hechos inventados o infundados"145 y sobre todo si, como se afirma, las funciones básicas de las stories consisten en llenar los vacíos dejados por la prueba incompleta o insuficiente acerca de los hechos relevantes. ${ }^{146}$ Algo similar es sostenido también por Neil MacCormick cuando dice que la coherencia narrativa es útil para determinar la verdad o la probabilidad de un hecho cuando no hay disponible una prueba directa. ${ }^{147}$

Desde una perspectiva como esa, en definitiva, la "evidencia empírica y el análisis lógico tienen un papel secundario en la verificación del carácter completo y la coherencia”, ${ }^{148}$ y es difícil determinar el valor probatorio de los elementos de prueba. ${ }^{149}$ Aunque los peligros del story-telling en los contextos judiciales incluyen también otros factores negativos, como, por ejemplo, la apelación a prejuicios, estereotipos ocultos y el uso de un lenguaje indebidamente emocional y de analogías dudosas, ${ }^{150}$ vale la pena centrarse en los factores que pueden llevar a la construcción de narrativas que tengan poco o nada que ver con la realidad de los hechos del caso. Muchas stories pueden estar basadas en hechos irrelevantes ${ }^{151}$ o en hechos que son inventados por el story-teller sin ninguna base racional o sustento en los elementos de prueba, y pueden ser usadas para afirmar la existencia de hechos que no han sido probados, solo a consecuencia del vacío

${ }^{142}$ Desarrollo este punto en otra parte: ver Taruffo, supra n. 24, p. 282.

${ }^{143}$ En forma más amplia, sobre esta versión y para mayores referencias, ver nuevamente Taruffo, supra n. 24 , p. 283.

${ }^{144}$ Ver Bennett-Feldman, supra, n. 134, at 33, y críticamente Twining, supra n. 6, p. 308.

145 Ver Twining, supra n. 6, p. 336.

${ }^{146}$ Ver Twining, supra n. 6, pp. 308, 336, 337.

147 Ver MacCormick, Coherente in Legal Justification, en Theorie der Normen. Festgabe für Ota Weinberger zum 65. Geburstag, ed. por W. Krawiets a.o., Berlin 1984, 48. Ver también Jackson, supra n. 6, p. 18.

${ }^{148}$ Ver nuevamente Twining, supra n. 6, p. 308.

149 Ver Menashe-Shamash, supra n. 21, p. 26.

${ }^{150}$ Ver Twining, supra n. 6, p. 336. Para un punto de vista crítico similar ver también MenasheShamash, supra n. 21, p. 5.

151 Ver nuevamente Twining, ibídem. 
que la falta de prueba produce en el curso de los sucesos narrados. Si se llenan vacíos por medio de la construcción de "toda" una story en realidad significa que los hechos no son verdaderos, porque no hay elementos de prueba que confirmen su existencia; ellos son presentados como si fueran verdaderos, solo porque calzan en el diseño total de la story. En una palabra, si un hecho que sería necesario para el orden y el desarrollo del relato "falta", porque no es probado, entonces el story-teller simplemente lo toma del "stock de conocimiento" disponible y lo inserta en el lugar correcto dentro del diseño del mosaico. En consecuencia, el mosaico de la story parece coherente y completo, sin que importe cuántas "piezas" falsas han sido insertadas. Todo esto significa, básicamente, que no puede pretenderse que esas narraciones sean respetuosas de la verdad de los hechos en cuestión. Su posible coherencia holista no agrega nada a su falta de veracidad.

Si estos argumentos pueden dar lugar a una defensa o a una crítica del sistema de jurados es algo que no puede ser discutido en esta sede. Sin embargo, cabe preguntarse si existen buenas razones para apoyar o recomendar un sistema en el que quienes juzgan los hechos construyan y relaten historias que a priori no reflejan los "reales" hechos del caso. La teoría holista de story-telling tiene la ventaja de iluminar estos aspectos de las narraciones, pero suscita el problema de considerar si la plausibilidad global de una story puede y debe ser el único factor que determine su aceptación dentro del contexto de la toma de decisiones judiciales.

\section{BuENAS NARRACIONES VERSUS NARRACIONES VERDADERAS}

Como Susan Haack ha señalado recientemente, el mismo acontecimiento puede ser objeto de varias descripciones verdaderas. ${ }^{152}$ En consecuencia, uno podría agregar, puede existir también un número (quizás mucho mayor) de descripciones falsas del mismo hecho. Se confirma así que el mismo suceso o conjunto de sucesos puede ser descrito de varias formas, y que algunas o muchas de ellas pueden ser verdaderas mientras algunas o muchas de ellas pueden ser falsas. Haack formula su comentario en términos epistemológicos generales, pero él resulta válido también de manera específica en el contexto judicial: como hemos visto antes, hay varios story-tellers trabajando en los procedimientos judiciales y se supone que ellos cuentan historias diferentes sobre el mismo suceso o conjunto de sucesos. Pero el comentario de Haack también implica que, cuando hay varias descripciones diferentes del mismo suceso o conjunto de sucesos -no importando cuántas de estas descripciones haya-siempre tiene sentido preguntar cuál de ellas es verdadera, suponiendo, por cierto, que alguna de ellas pueda ser verdadera. Si esto tiene sentido desde una perspectiva epistemológica general, no hay razón para negarle sentido dentro del contexto judicial. En dicho contexto, sin embargo, un concepto específico de verdad merece ser tomado en cuenta: un enunciado que describa un hecho es verdadero

${ }^{152}$ Ver Haack, Manifesto of a Passionate Moderate. Unfashionable Essays, Chicago-London, 1998, p. 157. 
cuando y en la medida que haya sido racionalmente confirmado por los elementos de prueba presentados al tribunal. ${ }^{153}$

La teoría, tanto general como judicial, del story-telling no habla en cambio de narraciones verdaderas, sino solo de good stories. ${ }^{154}$ En realidad, la idea de una buena narración es oscura y ambigua, ya que hay una variedad de propósitos en relación a los cuales una narración puede ser buena. ${ }^{155}$ Sin embargo, los requerimientos de una buena narración judicial parecen relativamente fáciles de determinar: una narración judicial será buena cuando sea plausible, cuando sea coherente con el "stock de conocimiento" que es típico de la audiencia y por lo tanto sea "familiar" para ella, cuando sea narrativamente coherente, ${ }^{156}$ y -por lo tanto- cuando sea persuasiva. ${ }^{157}$ Pero esta teoría -así como cualquier teoría de la verdad que se base en la coherencia del texto- se enfrenta a una objeción destructiva: las narraciones coherentes y persuasivas pueden ser completamente falsas. ${ }^{158}$ Basta con pensar en un testimonio que puede ser narrativamente coherente, pero falso, o también en una decisión judicial que puede también justificada en forma consistente, pero que no corresponde a las pruebas y por lo tanto a la realidad de los hechos, para encontrar ejemplos fáciles y claros de la distinción básica entre coherencia, consistencia o persuasividad y veracidad.

Por lo tanto, hay dos distinciones que debemos tomar en cuenta: la distinción entre narraciones verdaderas y falsas y la distinción entre buenas y malas narraciones. Las dos parejas no son equivalentes: ellas pueden, en cambio, ser combinadas, de modo que se obtiene un conjunto de cuatro situaciones diferentes. Para desarrollar esa combinación podemos estipular que una narración es verdadera cuando todas las aserciones relativas a hechos son verdaderas (es decir, correspondientes a la realidad de los hechos involucrados, sobre la base de los elementos de prueba disponibles), mientras que es falsa cuando al menos una de esas aserciones no está probada y por lo tanto no corresponde a la realidad de los sucesos descritos: "falsa" significa entonces total o parcialmente falsa.

a) Primera situación: puede tratarse de una buena narración, pero falsa. La novela de Grisham, al igual que miles de novelas bien escritas, son ejemplo de este tipo de

153 Ver supra, n. 72.

${ }^{154}$ En una perspectiva diferente, ver Burns, supra n. 6, at 2, según quien es posible en el juicio alcanzar una verdad que está más allá del story-telling.

155 Ver Twining, supra n. 6, p. 340, nota al pie 37.

${ }^{156}$ El concepto de "consistencia" o "coherencia" (los términos no son exactamente equivalentes, pero frecuentemente se usan como si lo fueran) ha sido objeto de amplias discusiones dentro de la teoría de la argumentación jurídica. Ver principalmente MacCormick, supra n. 147; Lenoble, "Narrative Coherence and the Limits of the Hermeneutic Paradigm", en Law, Interpretation and Reality. Interpretation in Legal Science: The Notion of Narrative Coherence, ibidem, at 204. Para una discusión comprehensiva ver Pino, "Coerenza e verità nell'argomentazione giuridica. Alcune riflessioni”, en Riv.int.fil.dir., 1998, p. 84.

157 Estos términos son una síntesis gruesa de las calificaciones que son adoptadas con el fin de definir los aspectos principales de un story-telling judicial efectivo. Ver especialmente a Twining, supra n. 6, pp. 283, $288,308,310,445$.

158 Ver principalmente Peczenik, On Law and Reason, Dordrecht a.o., 1989, p. 161. 
relatos: son buenas desde el punto de vista narrativo, pero -al pertenecer al dominio de la fantasía y la ficción- ni siquiera pretenden ser verdaderas. Por definición una novela -principalmente si es tomada holísticamente- es descriptivamente falsa, incluso cuando -como ocurre en el ejemplo de Grisham discutido más arriba- ella incluye algunas o incluso muchas aserciones que puedan ser identificadas como descriptivamente verdaderas.

b) Segunda situación: un mal relato puede además ser falso. Este es, desafortunadamente, el caso de muchas novelas mal escritas: pretenden narrar una historia, pero carecen de los elementos de una buena narrativa. En cualquier caso, como estas narraciones son novelas, no pretenden ser verdaderas, incluso cuando puedan incluir algunas afirmaciones verdaderas.

c) Tercera situación: puede tratarse de una buena narrativa que además es verdadera. Este es el caso, por ejemplo, de algunos relatos históricos que están escritos en una forma coherente, consistente, plausible y persuasiva, pero que a la vez son descriptivamente verdaderos, ya que representan fielmente el suceso o el conjunto de sucesos a los que se refieren. Este también puede ser el caso de las narraciones judiciales, cuando están bien construidas desde el punto de vista narrativo y al mismo tiempo están bien fundadas en las pruebas disponibles y por lo tanto corresponden a la realidad de los hechos en cuestión.

d) Cuarta situación: puede tratarse de una mala narración, que sin embargo es verdadera. ${ }^{159}$ Este es el caso de un relato histórico mal escrito, por ejemplo, porque no entrega una descripción completa de un conjunto o una cadena de sucesos, o porque narra circunstancias incoherentes e incluso contradictorias, pero que es descriptivamente verdadera porque refleja la realidad de las circunstancias de que se trata, en la medida que dichas circunstancias aparecen confirmadas por fuentes fidedignas de evidencia. Este puede ser también el caso de las narraciones judiciales: ellas pueden carecer de algunos aspectos de los "buenos" relatos, por ejemplo, porque las pruebas presentadas no entregan base suficiente para una reconstrucción completa, coherente y consistente del conjunto o cadena de sucesos relevantes, y solo permite confirmar algunos hechos aislados (o ningún hecho en absoluto). Sin embargo, esas "malas" narraciones pueden ser verdaderas, en la medida que se basen en elementos de prueba que tengan relación con los hechos en cuestión.

La relevancia y las funciones de estas cuatro clases de narraciones son obviamente diferentes dependiendo del tipo de contexto en que se produzcan y se usen. Por ejemplo, las narrativas de los tipos a) y b) son relevantes en el contexto de un concurso literario: si lo que está en juego es ganar el premio para la mejor novela policial del año, o algo por el estilo, la falsedad de la narración no es significativa, y la calidad narrativa de la historia es el único parámetro decisivo para la selección. En dicho contexto, una narra-

${ }^{159}$ Desde un punto de vista diferente, ver Coloma Correa, supra n. 50, p. 33, de acuerdo a quien las buenas historias son aquellas que están basadas en pruebas, y por lo tanto son verdaderas. 
tiva del tipo c) puede ser relevante, pero no porque es verdadera: simplemente porque está narrativamente bien escrita. En una competencia literaria la verdad de la historia no es relevante en absoluto: incluso podría ser contraproducente, si la demostración de veracidad de la historia requiere, por ejemplo, demasiadas referencias a las pruebas que confirman que la historia es verdadera. En ese mismo concurso, por supuesto, las narrativas del tipo d) van a ser dejadas de lado inmediatamente: una historia mal contada es definitivamente defectuosa y no podría nunca ganar ningún premio, a pesar de su veracidad.

La situación puede ser diferente si el problema consiste en evaluar la calidad de un relato histórico, porque en ese caso la verdad de la historia se transforma en uno de los parámetros relevantes para juzgar: por lo tanto, las narrativas del tipo c) serían las mejores, pero también las narrativas del tipo d) aunque sean defectuosas desde el punto de vista literario, pueden ser apreciadas, en la medida en que sean verdaderas.

En cuanto al contexto judicial, parece que las narrativas del tipo a) son importantes, especialmente para los/as abogados/as. Como se dijo arriba, un abogado no tiene la obligación de decir la verdad o ayudar a su búsqueda ${ }^{160}$ y su historia tiene que ser solo útil para ganar el caso. Entonces, una historia narrativamente buena puede ser muy útil, aunque sea descriptivamente falsa, sobre todo si su propósito final es persuadir a un juez (o un trier of fact) "holista", de quien no se espera que esté dedicado a establecer la verdad sobre los hechos en cuestión. También para ese tipo de juzgador las narrativas del tipo a) son significativas, y por la misma razón: para ese juzgador una narración tiene que ser buena desde el punto de vista narrativo con el fin de ser persuasiva, y con el fin de ser aceptada como una reconstrucción adecuada de los hechos. Si la narración es o no realmente verdadera a la luz de las pruebas, es algo que no importa: una buena narración, aunque falsa, bien puede ser la base de una sentencia (o un veredicto) holista.

Si, por el contrario, nos imaginamos que quien juzga los hechos está interesado en tomar una decisión ajustada a la realidad del caso, y en basar sus descubrimientos en una valoración racional de las pruebas presentadas en juicio, entonces el tipo de narrativa óptima es claramente la del tipo c). Un relato que corresponda descriptivamente a la realidad de los hechos según se desprende de las pruebas, y que también sea narrativamente coherente, consistente, completo y plausible, es el mejor tipo de narración que puede ser construido por un juez.

En dicha situación, ¿qué pasa con la narración del tipo d)? Prima facie, uno podría decir que para un abogado no es interesante: la historia puede ser verdadera, pero si es narrativamente mala puede no ser útil para ganar la causa. Un abogado usaría un relato verdadero, pero narrativamente malo, sólo como un desesperado último recurso. Si nos situamos en cambio en el punto de vista de quien juzga los hechos, ese tipo de narración merece un mayor análisis.

Asumamos que los hechos materiales en los que se basa una demanda de indemnización de perjuicios son descritos por estos enunciados:

${ }^{160}$ Ver supra, $\S 2.3$. sub a). 
1) Al momento $M$, en el lugar $\mathrm{L}$, el sujeto A realizó la acción $X$

2) La acción $X$ hirió al sujeto $B$

3) El sujeto $B$ fue herido de tal y tal manera

Si las pruebas aportadas en juicio han permitido establecer que las afirmaciones 1), 2) y 3) son verdaderas, estas afirmaciones pueden ser ordenadas para formar una narrativa coherente, consistente, plausible y posiblemente completa de la secuencia de hechos. Entonces, tendremos una narración del tipo c): buena y verdadera. Pero si los elementos de prueba no confirman suficientemente -por ejemplo- el enunciado 2), entonces surge un problema. ¿Qué tipo de historia puede ser relatada en esa situación? Un partidario de la teoría holista sugeriría que quien juzga los hechos llene ese vacío dejado por la falta de prueba de la aserción 2) haciendo referencia a cualquier conocimiento de sentido común de acuerdo al cual en situaciones similares "normalmente" existe una conexión causal entre los hechos del tipo descrito en la afirmación 1) y los hechos descritos en la afirmación 3). En consecuencia, dicho juzgador podría construir una buena narración -coherente, plausible, consistente y completa-de los hechos. Sin embargo, esa narración va a ser del tipo b) descrito arriba, ya que podría ser falsa con referencia a la afirmación 2): en realidad, nadie sabe si A realmente hirió a B, y por lo tanto una aserción en ese sentido no puede ser tomada como verdadera sobre la base de las pruebas disponibles. Una situación más clara aún puede ocurrir si hay pruebas que muestren que la acción X no hirió a B. Incluso en esa situación el juzgador holista puede construir el mismo relato, simplemente no considerando la evidencia que está en contra de una narración de los hechos buena, completa y "normal".

Un partidario de la aproximación analítica o atomista diría en cambio que si la afirmación 2) no resulta probada, falta una parte importante de la historia hipotética, porque no se puede establecer una relación causal entre los enunciados 1) y 3). En consecuencia, un juzgador "analítico" no podría construir una narración completa y consistente de la situación involucrada: simplemente podría decir que, sobre la base de las pruebas disponibles, es verdad que A realizó la acción X y que B fue herido, pero que no existe una relación causal entre ambos eventos. Una conclusión de este tipo resultaría incluso mejor fundada si las pruebas permitieran establecer que el enunciado 2) no es verdadero. Desde el punto de vista narrativo, se trataría de un mal relato: fragmentado, incoherente e incompleto. Sin embargo, esa narración sería verdadera, porque reflejaría fielmente el resultado probatorio. Sería por lo tanto una narración del tipo d) descrito anteriormente. La diferencia obvia entre los dos tipos de historias que pueden ser relatadas en la misma situación reside en que el juzgador holista construiría una narración del tipo b) y concluiría que A es responsable por las lesiones sufridas por $\mathrm{B}$, mientras que un juzgador analítico concluiría, sobre la base de una narración del tipo d), que A no es responsable de esas lesiones.

Este análisis esquemático de las principales situaciones que típicamente pueden ocurrir en los contextos judiciales muestra que las buenas narraciones pueden ser falsas y que las narraciones verdaderas pueden ser sin embargo malas narraciones. No es fácil establecer si, en la práctica, y en todos los sistemas procesales, las buenas narraciones 
desplazan a las narraciones verdaderas, como dice Twining. ${ }^{161}$ Probablemente tienden a preferirse las buenas narraciones, incluso si son falsas, más que las narraciones verdaderas, especialmente cuando los relatos verdaderos son narrativamente defectuosos. Sin embargo, esta preferencia puede variar, dependiendo del tipo de juzgador (jurado o juez profesional), y ciertamente dependiendo del tipo de contexto en que la story judicial sea relatada. Un reportero puede preferir un buen relato sin preocuparse mucho acerca de su veracidad, mientras que un juez puede preferir el relato verdadero, incluso si es narrativamente pobre. En todo caso, el problema que nos preocupa se refiere al tipo de narración que debe ser preferido como fundamento para una decisión judicial. Si compartimos el supuesto que hay una diferencia entre un proceso judicial y un concurso literario, podemos inclinarnos a creer que solo las narraciones verdaderas entregan una reconstrucción precisa de los hechos en cuestión. Las buenas narraciones que incluyen enunciados falsos o infundados llevarían probablemente a una decisión defectuosa, imprecisa y no confiable. Esta es la razón principal que explica por qué sostener que "el razonamiento narrativo, aunque necesario, es inherentemente defectuoso" 162 puede ser quizás un poco radical, pero apunta sustancialmente en una dirección correcta, al menos cuando se refiere a las aproximaciones narrativistas más extremas al problema de la decisión judicial acerca de los hechos.

Sin embargo, incluso tomando en consideración solo las narraciones verdaderas, hay al menos un sentido en el que los aspectos narrativos de un relato pueden ser relevantes. Imagínense que los hechos materiales del caso $\mathrm{H} 1, \mathrm{H} 2, \mathrm{H} 3 \ldots \mathrm{HN}$ estuvieran probados de acuerdo a los estándares probatorios usuales. Entonces, cualquier historia en relación con $\mathrm{H} 1$...HN sería analíticamente verdadera. Siguiendo nuevamente a Susan Haack, ${ }^{163}$ varias historias verdaderas pueden ser narradas acerca de tales hechos: algunas de ellas pueden ser buenas y otras pueden ser narrativamente defectuosas, dependiendo de cómo se combinan los hechos en un conjunto más o menos coherente de sucesos. En dicha situación, un relato narrativamente bueno debe ser preferido a uno defectuoso, ya que el primero entrega una reconstrucción más coherente y plausible de los hechos en cuestión. Este relato pertenecería al tipo c) descrito arriba. Usando nuevamente la metáfora del mosaico: si tenemos algunas piezas de vidrio de colores, y todas esas piezas son de buena calidad, podemos ensamblarlas de distintas maneras. En algunos casos, el diseño general va a tener sentido, mientras que en otros casos (como ocurriría si lanzamos las piezas al azar) no lo tendría; más aún, un diseño con sentido puede ser preferible a otros diseños con sentido. Teniendo que elegir un diseño entre todos los posibles, es razonable escoger el que combina las piezas en el diseño más bonito. En forma similar, teniendo que elegir entre diferentes relatos, cada uno de ellos compuesto de aserciones verdaderas acerca de los hechos, incluso un juzgador "analítico" escogería racionalmente la comparativamente

\footnotetext{
161 Ver Twining, supra n. 6, p. 336.

162 Ver Menashe-Shamash, supra n. 21, p. 14.

163 Ver supra, p. 152.
} 
"mejor" narración de los hechos en cuestión. ${ }^{164}$ En una palabra: los aspectos narrativos de una historia no son suficientes, por sí mismos, para determinar la preferencia por esa historia; sin embargo, esos aspectos pueden ser considerados como parámetros de preferencia entre los varios relatos verdaderos que narran los mismos hechos.

\section{BIBLIOGRAFÍA}

Amsterdam-Bruner, Minding the Law, Cambridge, Mass.-London, 2002.

-Law's Stories. Narratives and Rhetoric in the Law, New Haven-London, 1996.

Bruner, Making Stories. Law, Literature, Life, Cambridge, Mass.-London, 2002.

Ferrer Beltrán, Prueba y verdad en el derecho, Madrid-Barcelona, 2002.

Friedman, The Horizontal Society, New Haven-London, 1999.

Gadamer, Wabrheit und Methode, Tübingen, 1972.

Goldman, Knowledge in a Social World, Oxford, 1999.

-Reference Manual on Scientific Evidence, Federal Judicial Center, 2000.

Schauer, Profiles, Probabilities and Stereotypes, Cambridge, Mass.-London, 2003.

SeArle, Mind, language and society, New York, 1999.

TARUfFo, La prueba de los hechos, tr.sp. Madrid, 2002.

TARUFFo, Sobre las Fronteras. Escritos sobre la justicia civil, tr.sp. Bogotá, 2006.

TwINING, Rethinking Evidence. Exploratory Essays, 2 ed., Cambridge, 2006.

${ }^{164}$ Discuto extensamente este tipo de argumento en otro lugar. Ver Taruffo, supra, n. 24, p. 293. Un argumento similar es usado en metaepistemología, cuando se dice que como varias teorías científicas pueden referirse a los mismos hechos, entonces la elección entre ellas -tomadas como un conjunto holístico de afirmaciones- se basa en factores como la simplicidad, la utilidad y la coherencia de la teoría: ver, por ejemplo, Pino, supra n. 156, p. 96. 